\title{
Laser-induced Damage Initiated on the Surface of Particle Contamina- tion Fused Silica at 1064nm
}

Kenneth Jerome Francis Michlitsch

(B.S. Thesis)

June 1998 


\section{DISCLAIMER}

This document was prepared as an account of work sponsored by an agency of the United States Government. Neither the United States Government nor the University of California nor any of their employees, makes any warranty, express or implied, or assumes any legal liability or responsibility for the accuracy, completeness, or usefulness of any information, apparatus, product, or process disclosed, or represents that its use would not infringe privately owned rights. Reference herein to any specific commercial product, process, or service by trade name, trademark, manufacturer, or otherwise, does nol necessarily constitute or imply its endorsement, recommendation, or favoring by the United States Government or the University of California. The views and opinions of authors expressed herein do not necessarily state or reflect those of the United States Government or the University of California, and shall not be used for advertising or product endorsement purposes.

This report has been reproduced directly from the best available copy.

Available to DOE and DOE contractors from the Office of Scientific and Technical Information P.O. Box 62, Oak Ridge, TN 37831

Prices available from (615) 576-8401, FTS 626-8401

$\Lambda$ vailable to the public from the National Technical Information Service

US Department of Commerce 5285 Port Royal Rd., Springfield, VA 22161 
UCRL-LR-130583

Distribution Category UC-700

\section{Laser-induced Damage Initiated on the Surface of Particle Contamina- tion \\ Fused Silica at $1064 \mathrm{~nm}$}

Kenneth Jerome Francis Michlitsch

(B.S. Thesis)

June 1998

LAWRENCE LIVERMORE NATIONAL LABORATORY University of California • Livermore, California • 94551 



\section{Laser-induced Damage Initiated on the Surface of Particle Contaminated Fused Silica Optics at 1064nm}

by

Kenneth Jerome Francis Michlitsch
Submitted to the Department of Mechanical Engineering in Partial Fulfillment of the Requirements for the Degree of
Bachelor of Science

at the

Massachusetts Institute of Technology

June 1998

1997 Kenneth Jerome Francis Michlitsch

All rights reserved

The author hereby grants to MIT permission to reproduce and to distribute publicly paper and electronic copies of this thesis document in whole or in part.

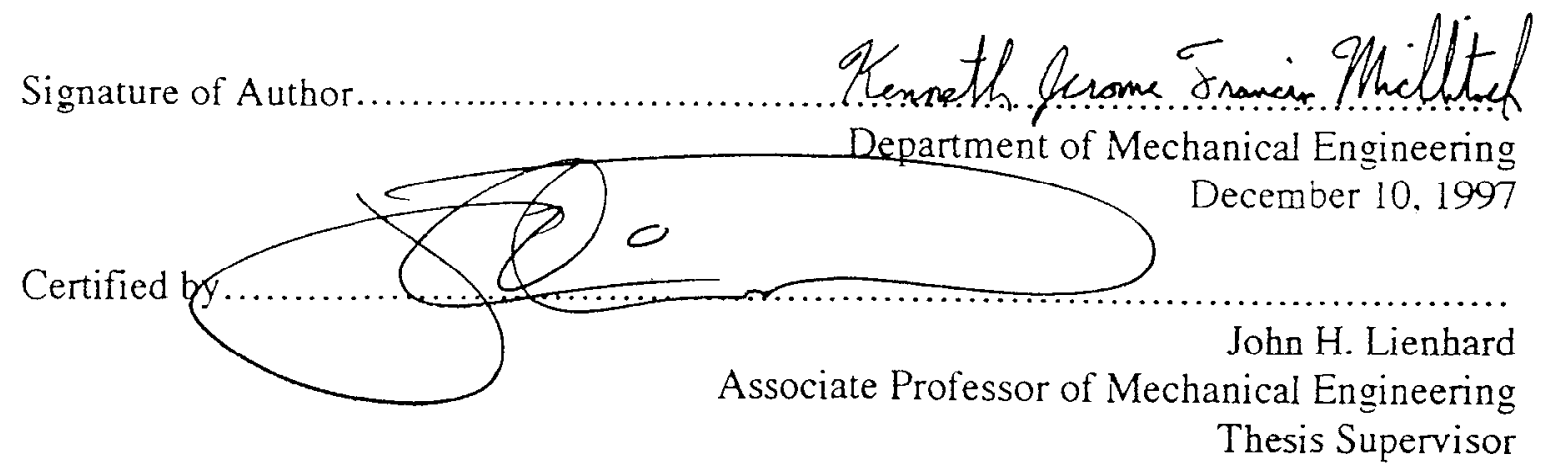

Accepted by

Derek Rowell

Professor of Mechanical Engineering Chairman. Undergraduate Thesis Committee 


\title{
Laser-induced Damage Initiated on the Surface of Particle Contaminated Fused Silica Optics at 1064nm
}

\author{
by \\ Kenneth Jerome Francis Michlitsch \\ Submitted to the Department of Mechanical Engineering \\ in Partal Fulfillment of the Requirements \\ for the Degrec of Bachelor of Science
}

\begin{abstract}
An experimental study was undertahen to quantify the effects of contamination particles on the damage threshold "I laser-illuminated fused silica optics and set cleanliness requircments for optics on the beam line of the National Ignition Facility at Lawrence Livermore National Laboratory. Circular contamination particles were sputter-deposited onto fused silica windows which were then illuminated repetitively using a $1064 \mathrm{~nm}$ laser. A variety of contamnants were tested including metals, oxides, and organics. Tests were conducted with particles on the input and output surfaces of the window, and the morphological features of the damage were very reproducible. A plasma often ignited at the contamination particle; its intensity was dependent upon the mass of the contaminant. Input surface damage was characteristically more severe than output surface damage. The size of the damaged area scaled with the size of the particle. On a few occasions, catastrophic damage (cracking or ablation of the substrate) initiated on the output surface due to contamination particles on either the input or output surface. From damage growth plots, predictions can be made about the severity of damage expected from contamination particles of known size and material.
\end{abstract}

Thesis Supervisor: John H Lienhard

Title: Associate Professor of Mechanical Engineering 


\section{TABLE OF CONTENTS}

$\underline{\text { Section }}$

Page Number

10 INTRODUCTION . .4

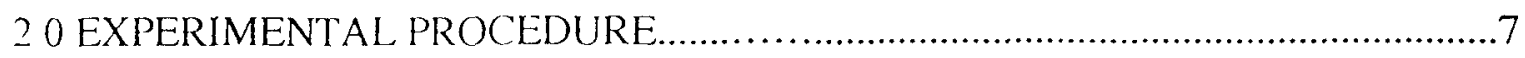

2.1 Preparation of Contaminated Optics....................................................................

2.2 Laser Damage Testing \& Characterization............................................................8

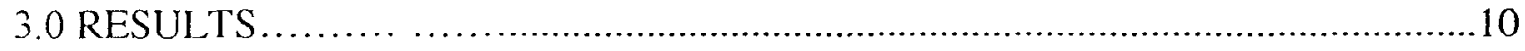

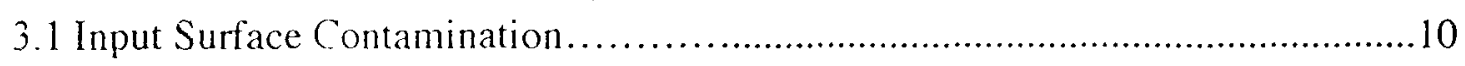

3.1.1 Input Surface Morphologies...............................................................11

3.1.2 Input Surface Damage Size.....................................................18

3.2 Output Surface Contamination.........................................25

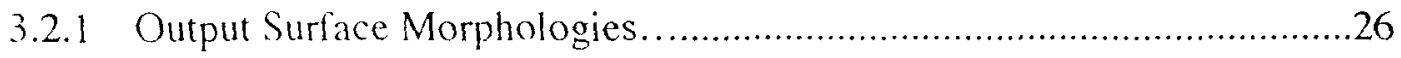

3.2.2 Output Surface Damage Size.....................................................33

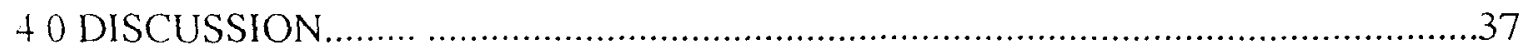

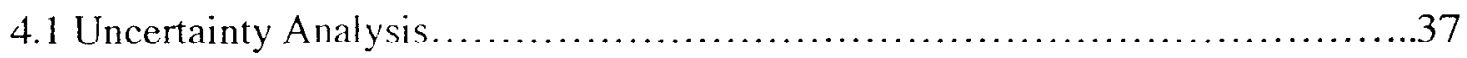

4.2 Catastrophic Damage ...................................................

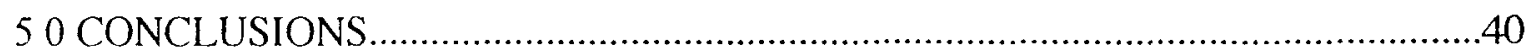

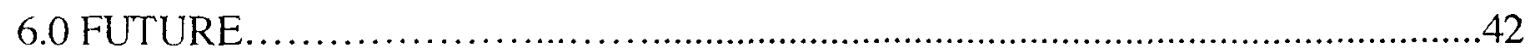

6.1 Ramping Studies...................................................... 42

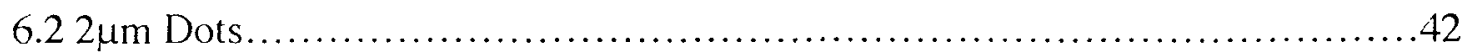

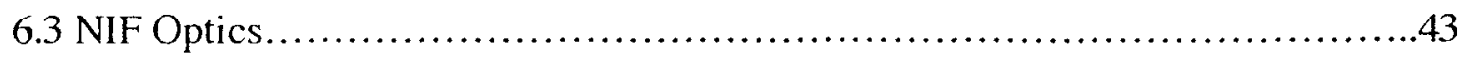

$6.4355 \mathrm{~nm}$ Laser Illumination............................................. 43

6.5 Modeling and the Mechanism of Catastrophic Damage........................43

7.0 ACKNOWLEDGMENTS .....................................................

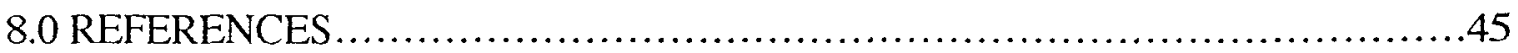




\section{INTRODUCTION}

The use of high fluence lasers to achieve inertial confinement fusion with energy gain may soon be a reality as efforts are quickly moving forward on both the National Ignition Facility (NIF) at Lawrence Livermore National Laboratory (LLNL) and the Laser Mégajoule (I.M.I) in France. These systems will subject optics to fluences far above those currently observed on any large system. As designers push fluence levels ever closer to the damage thresholds of optical components, the need arises to better understand optical behavior under such intense illumination. Limitations inherent in the bulk or surface properties of optics can lead to laser-induced damage. Contamination particles on the surface can aggravate the damage. The survivability of beam line optics is partially dependent upon the type and size of contamination lying on the optical surfaces. In order to predict survivability and set cleanliness requirements which balance cleaning costs against an acceptable optic serviceable lifetime, the effects of surface contamination must be characterized and quantified.

Optics development efforts normally focus on reducing imperfections and improving intrinsic properties $[1-3]$. Although contamination effects are known to lower the damage thresholds of optical components $[4-9,10-16]$, little work has been done to quantify or characterize these effects. This article presents the initial results of a study designed to understand the effects of surface contamination on the survivability and functional damage threshold of NIF optics. The initial matrix of variables to be studied included contamination particle material (metals, oxides, organics); particle size, shape, thickness. mass, and material properties; adherence between the substrate and the contaminant; laser pulselength and wavelength; substrate material (fused silica, 
phosphate glass, KDP crystal. multilayer mirrors, polarizers); environment (air vs. vacuum); fluence level: number of shots: and shot repetition rate.

This article presents the results of all fused silica tests run at $1064 \mathrm{~nm}$ and at a constant fluence of $40 \mathrm{~J} / \mathrm{cm}^{2}$ The materials discussed include metals (Al, Ti, stainless steel, $\mathrm{Cu}, \mathrm{W}, \mathrm{Au}$ ), oxides $\left(\mathrm{Al}_{2} \mathrm{O}_{3}, \mathrm{TiO}_{2}, \mathrm{ZrO}_{2}\right.$ ), and organics (plastic, carbon, Teflon, hair). The tests conducted " ere 1 -on-1 (single shot), 20-on-1 (20 shots with 3 seconds between shots) and S-on-1 $(600$ shots at a repetition rate of $10 \mathrm{~Hz})$. The tests were conducted at contamination sites on both the input and output surfaces of the fused silica windows.

An artificial contamination lechnique was developed in order to allow systematic control of the test conditions including particle shape and size. $1 \mu \mathrm{m}$ thick dots were sputter-deposited through silicon nitride windows onto the fused silica windows. The dots ranged in size from 10 to $250 \mu \mathrm{m}$. Contamination particles larger than $250 \mu \mathrm{m}$ were not studied since it has been shown that obscurations larger than $280 \mu \mathrm{m}$ will not be tolerable on NIF optics 1171 . To determine whether the damage observed from the artificial contamination technique closely approximated damage occurring from real contaminants, the substrates were also tested with high purity Al shavings, and the results were qualitatively the same as those observed from testing sputtered Al dots.

The following discussion focuses on the morphological features of the laser-induced damage which was categorized into 3 broad groups: benign, massive, and catastrophic. Benign damage does not affect the laser performance of the optic with respect to NIF requirements. Massive damage affects performance beyond acceptable limits set for NIF. Catastrophic damage is cracking or ablation of the glass which continues to grow 
with repetitive illumination. The damage morphologies were consistent and reproducible for particles of different sises but quite different for particles of different materials and for contamination on the outpul surface as opposed to the input surface.

The dependence of damage size on contamination size has been examined in great detail, and the experimental results are being used to set first-order cleanliness specifications for NIF optics and quantify the functional damage threshold of fused silica window's illuminated at $40.1 / \mathrm{cm}^{2}$ by identifying the particle sizes which can induce benign. massive and catastrophic damage.

The report which follows describes the methodology employed during testing in an experimental procedure secuon. Results are then presented with an appropriate error analysis that includes both bias and precision uncertainty. The discussion section discusses the mechanism of damage and the methodology employed in the error analysis. Conclusions and recommendations are then provided, and future work in this area of study is outlined. 


\section{EXPERIMENTAL PROCEDURE}

The experiments were conducted in two major steps which are outlined in Sections 2.1 and 2.2. First, contaminated optics were prepared. Laser damage testing and characterization was then performed. The optics were contaminated by etching silicon nitride membranes with circular openings of six different sizes $(10,20,30,50,150$, and $250 \mu \mathrm{m})$. Contaminants were then deposited by sputtering through the membranes onto fused silica substrates. Laser damage tests at $1064 \mathrm{~nm}$ and a fluence of $40 \mathrm{~J} / \mathrm{cm}^{2}$ were conducted on the $1 \mu \mathrm{m}$ thick contaminants deposited on the substrates. Laser-induced damage initiated at contamination particles on the surface was then characterized by Nomarski optical microscopy, atomic force microscopy (AFM), and measurements of the damage size.

\subsection{Preparation of Contaminated Optics}

Low stress CVD silicon nitride was deposited onto 3" silicon wafers. Small holes were etched into the nitride on the front side using standard photolithography techniques, and larger squares were etched on the back. The wafers were then dipped for several hours in a bath of $\mathrm{KOH}$ at $70^{\circ} \mathrm{C}$ to anisotropically etch the silicon and open the windows.

The masks were then placed onto $1.14 \mathrm{~cm}$ thick UV grade fused silica substrates. Contaminants were sputter deposited through masks and onto the substrates until the thickness of the deposit reached $1 \mu \mathrm{m}$. For the tests conducted with Al shavings (as well as the limited tests conducted with Teflon, hair, and stainless steel spheres) the samples were contaminated by breathing on the substrate for adhesion. High purity Al was then filed over the substrate. 


\subsection{Laser Damage Testing \& Characterization}

The laser damage tests were carried out using an $8.6 \mathrm{~ns}$ pulse from a $1064 \mathrm{~nm}$ Nd:YAG laser. The laser was focused to provide a far field circular Gaussian beam with a diameter of about $1 \mathrm{~mm}$ at $1 / \mathrm{e}^{2}$ of the maximum intensity. The beam profile was recorded for each shot, and the peak fluence was computed. Each site was irradiated with a sequence of single laser pulses. The tests were conducted in S-polarization at a near normal incidence of $1^{\circ}$. The damage threshold of the surface of the fused silica samples was tested to establish a baseline; the threshold of the uncontaminated surface was above $50 \mathrm{~J} / \mathrm{cm}^{2}$. The fluence during tests was $40 \mathrm{~J} / \mathrm{cm}^{2}$. A schematic of the beam line is presented in Figure 1. A more thorough discussion of the laser damage test facility is given in Reference 18.

\section{Laser Damage Test System}

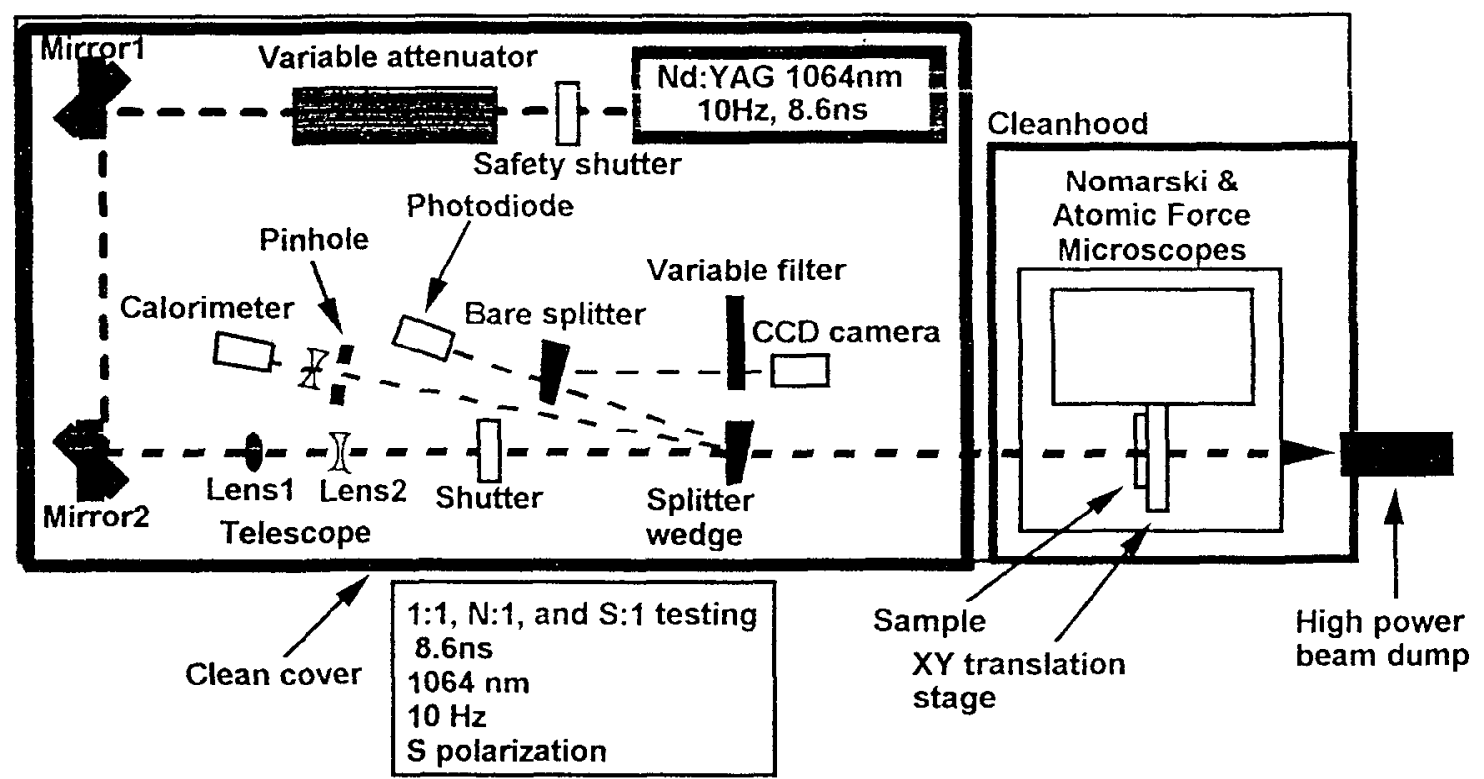

Fig. 1: Schematic of 1064nm laser damage test system. The laser was focused to provide a far field circular Gaussian beam with a diameter of about $1 \mathrm{~mm}$ at $1 / \mathrm{e}^{2}$ of the maximum intensity. The beam profile was recorded for each shot, and the peak fluence was recorded. Laser damage tests were conducted in S-polarization at $1^{\circ}$ incidence angle . The fluence was $40 \mathrm{~J} / \mathrm{cm}^{2}$, and the pulselength was $8.6 \mathrm{~ns}$. 
In order to obtain sufficient statistical information, six particle sizes were investigated $(10,20.30,50,150$, and $250 \mu \mathrm{m}) .5$ dots (contamination sites) of each size were tested on both the input and output surfaces for a total of 60 testing sites. The region surrounding each dot was characterized and photographed before illumination, after 1 shot, after 20 shots with 3 seconds between illuminations, and after 600 shots at a $10 \mathrm{~Hz}$ repetition rate (1-on-1. 20-on-1, and S-on-ltesting) by Nomarski optical microscopy in order to trach the initiation and growth of laser-induced damage upon repetitive illumination and to study the surface morphology of the damage. Atomic Force Microscopy (AFM) was also used to measure the height or depth of the different damage morphologies. 240 characterizations and measurements comprised a full input and output surface study of a contamination material.

Al shavings were also tested on both the input and output surfaces of the substrate. Studying this form of contamination was determined feasible but much more difficult, time consuming, and less standardized than sputtered contamination. Results obtained from $\mathrm{Al}$ shavings closely mirrored those obtained from sputtered $\mathrm{Al}$ dots. 


\section{RESULTS}

The experiments yelded iery reproducible damage morphologies. Damage was classified into three areas benign. massive, and catastrophic. As described previously, benign damage does not allect the laser performance of the optic with respect to NIF requirements, massive damage affects performance beyond acceptable limits set for NIF, and catastrophic damage is cracking or ablation of the glass which continues to grow with repetitive illumination Damage behavior (morphology and size) was found to vary between input and output surfaces and for different materials. However, for contaminants of the same sice and material on the same surface, damage behavior was relatively consistent and efforts are currently underway to model laser damage initiated at contamination [19-21].

The results of tests conducted with input surface contamination are discussed first. This is followed by a discussion of the results obtained with output surface contamination.

\subsection{Input Surface Contamination}

Damage initiated at two places with input surface contamination. The first was at the contamination dot. A plasma usually ignited at the contaminant on the first shot; the contaminant was then molten and redeposited on the surface, often over a larger area than the original dot. Subsequent pulses then interacted with the new deposit and plasmas ignited until a majority of the contaminant was ablated. At that point, the damage site was stable and did not grow or change upon further irradiation. Atomic 
force microscopy showed that damage usually did not penetrate more than a few hundred nanometers into the substrate surface.

Much less frequently, damage initiated on the output surface of the window directly behind the location of the dot. This damage usually grew very quickly to calastrophic proportions. A pit initiated on the output surface, and subsequent shots drilled into the glass.

The characterization of individual contaminants follows. Both morphologies and damage sizes are presented.

\subsubsection{Input Surface Morphologies}

Figures 2-4 show the typical input surface damage morphologies for all materials tested. The $150 \mu \mathrm{m}$ contamination particles on the input surface of the substrate are shown before irradiation, after 1-on-1, 20-on-1, and S-on-1 testing. For metals, the morphologies that have been characterized are $\mathrm{Al}, \mathrm{Ti}, \mathrm{Cu}, \mathrm{W}, \mathrm{Au}$, and stainless steel. Of the oxides, $\mathrm{Al}_{2} \mathrm{O}_{3}, \mathrm{TiO}_{2}$, and $\mathrm{ZrO}_{2}$ were examined. Organics which have been studied include carbon, plastic. Teflon, and hair. Morphologies varied from material to material and for different contaminant sizes. Figure 5 shows the testing of all six $\mathrm{Cu}$ contaminant sizes on the input surface of the fused silica. It represents $1 / 5$ of a full input surface study for a contamination material. 


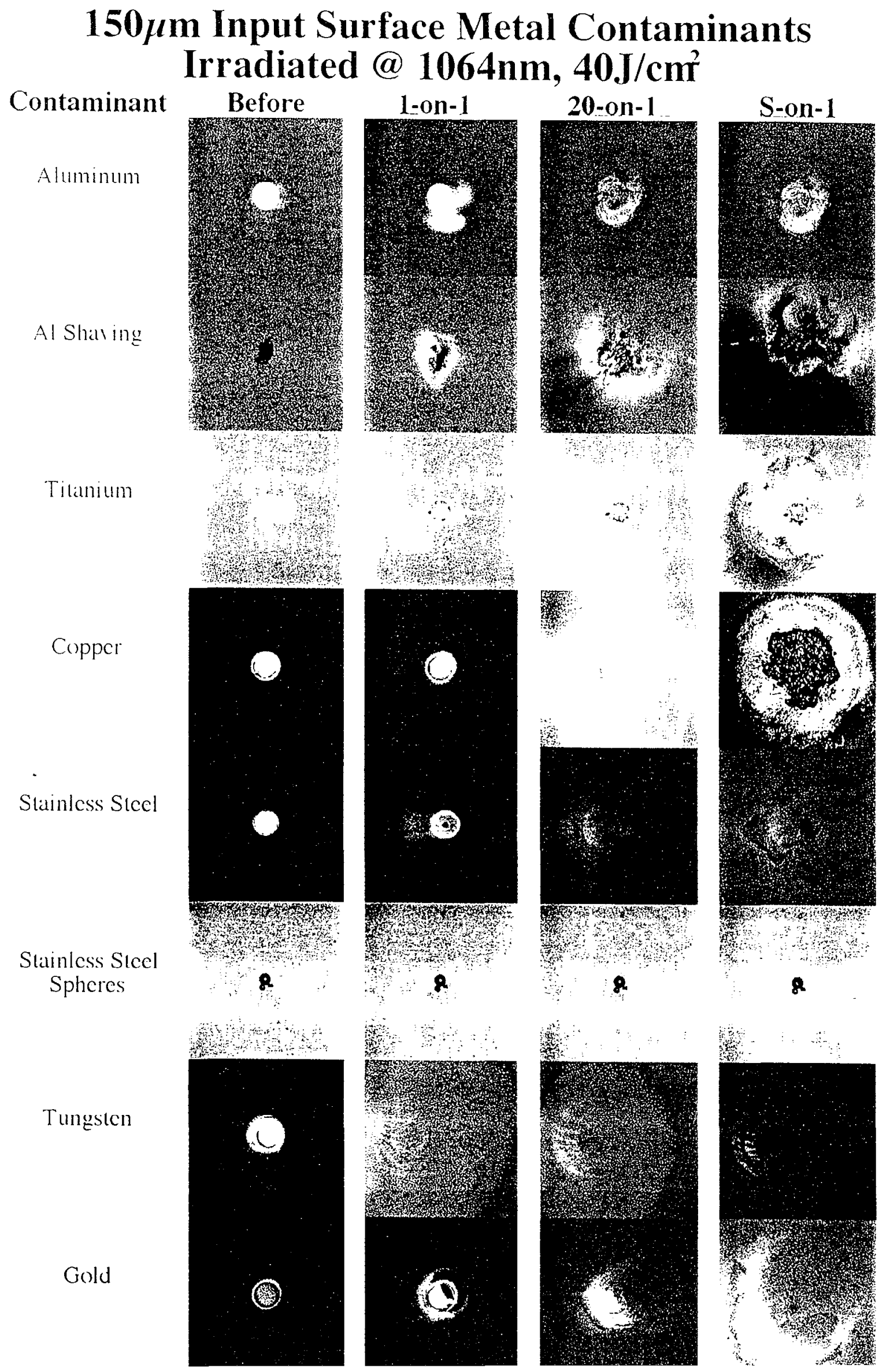


Fig. 2: Nomarski optical micrographs of the input surface damage morphologies initiated by $150 \mu \mathrm{m}$ contamination particles are displayed before irradiation; and after 1-on-1, 20on-1, and S-on-1 testing for all metals tested. The morphologies observed were similar for different metals and uaried mainly in severity. Scalding, pitting, and debris are characteristically observed. The Titamum dot also caused benign output surfacc damage which did not grow during repetitive illumination. 


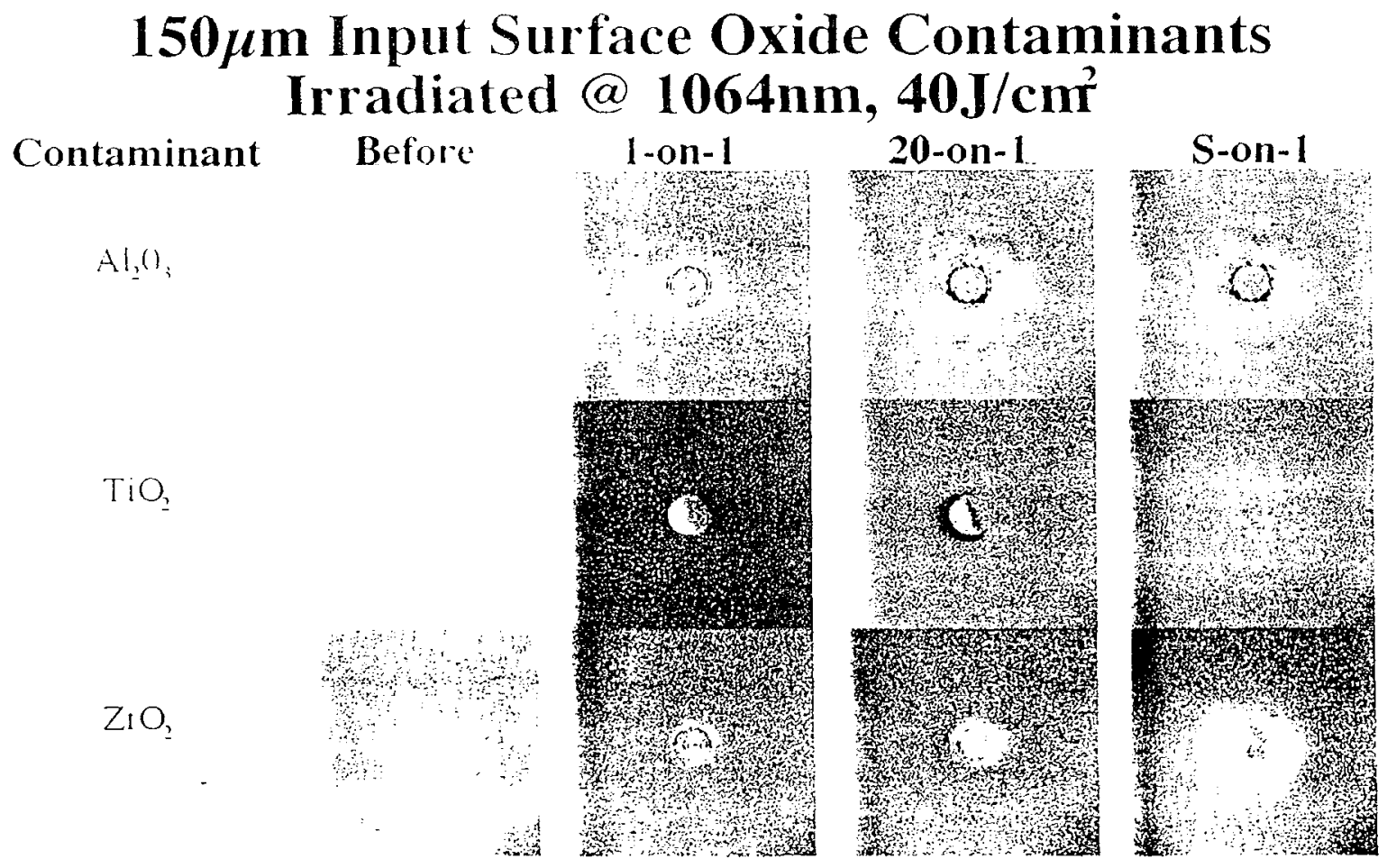

Fig. 3: Nomarski optical micrographs of the input surface damage morphologies initiated by $150 \mu \mathrm{m}$ contamination particles are displayed before irradiation; and after 1-on-1, 20on-1. and S-on-1 testing for all oxides tested. The morphologies observed were similar for different oxides. Damage initiated by oxides is relatively benign unless output surface damage is initiated by pitting or cracking of the substrate. This damage usually grows to catastrophic size and is most commonly initiated by oxides. 


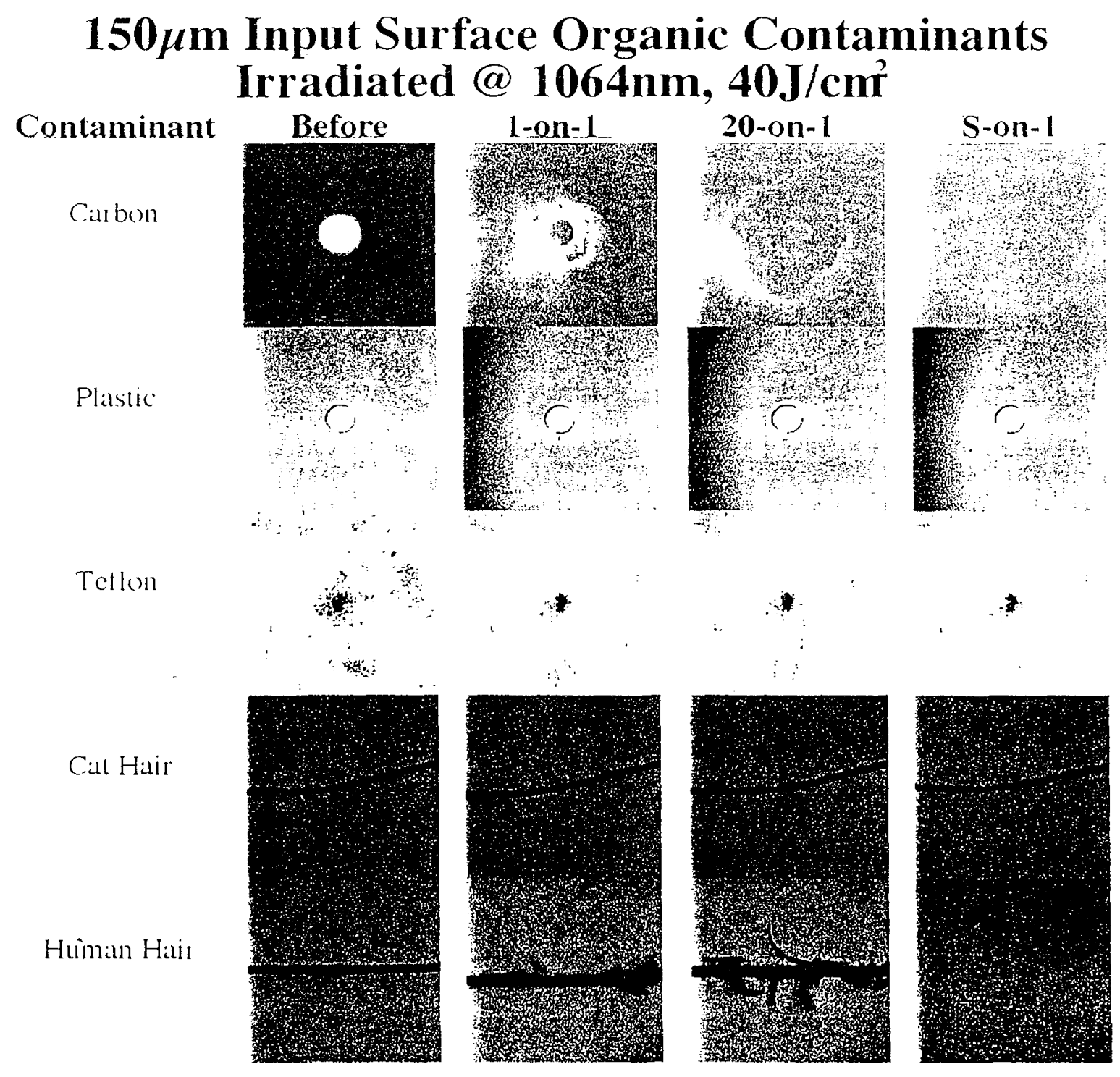

Fig. 4: Nomarski optical micrographs of the input surface damage morphologies initiated by $150 \mu \mathrm{m}$ contamination particles are displayed before irradiation; and after 1-on-1, 20on-1, and S-on-1 testing for all organics tested. The morphologies observed were not characteristic for different organics. Carbon-initiated damage spread a great deal while plastic and Teflon showed little reaction to irradiation. Human hair was destroyed by the beam. 


\section{Input Surface Copper Contaminants Irradiated@1064nm, 40J/cm²}

Size

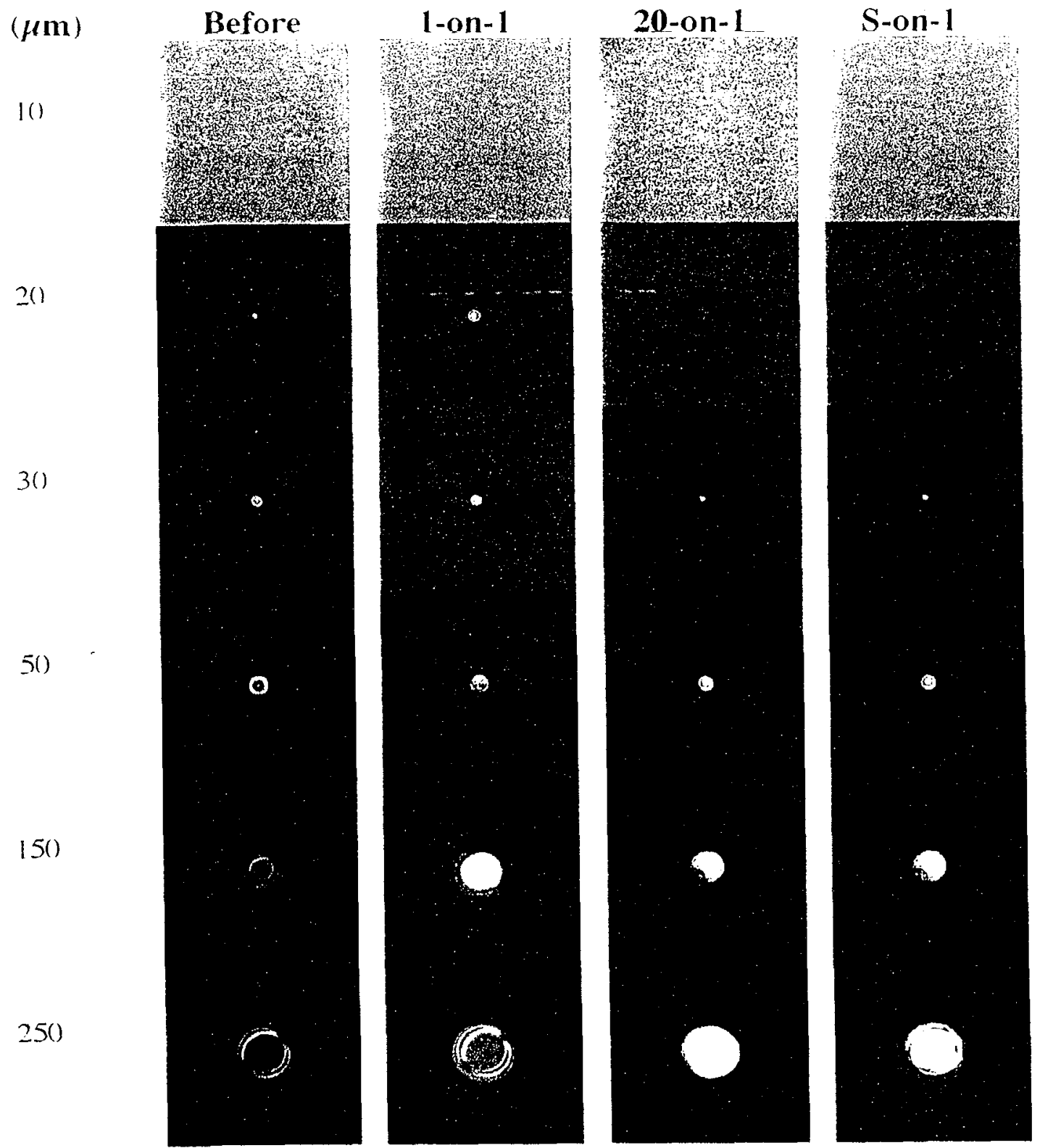

Fig. 5: Nomarski optical micrographs of the 6 sputtered dot sizes for input surface $\mathrm{Cu}$ contamination are shown before irradiation; and after 1-on-1, 20-on-1, and S-on-1 testing (600 shots at a $10 \mathrm{~Hz}$ repetition rate). Input surface damage often continues to grow during repetitive illumination. Larger dots can initiate more severe damage. Copper contamination initiates relatively benign damage as compared to other materials. If the contaminant is removed, a scald is seen where it was located. Pitting surrounds, and debris is scattered on the outskirts of the damage. The $150 \mu \mathrm{m}$ contaminant initiated catastrophic damage on the output surface (see Fig. 10). This figure represents $1 / 5$ of a full input surface contamination study. 
While the initial findings for Al contamination have already been reported elsewhere 1221, the information is briefly presented here in the context of other contaminants irradiated at $1064 \mathrm{~nm}$. Damage initiated at input surface Al showed a characteristic burnt surface. Bumps were visible in the central region where the Al was located. Craters or pits surrounded the center, and debris was scattered farther away.

Al shaving morphologies closely mirrored those of sputtered Al. A plasma ignited at the shaving on the first shot, the Al was redeposited and acted as a sputtered dot. The burnt surface, bumps. pits, and debris characteristic of the sputtered contaminant were all visible.

Ti initiated input surface damage was more severe than Al-initiated damage. A blister on the surface was visible where the dot had been located. Pitting surrounded, and small raised clumps of $\mathrm{Ti}$ were located where the material redeposited after the first shot. During repetitive illumination. these clumps continued to spread the damaged area. Debris was again scattered around the outer regions of the damage.

Sputtered stainless steel \& Cu both initiated damage which showed blistering, pitting, and debris. Although the ('u damage sites produced were usually not particularly large, the morphology appeared very severe and occasionally caused damage on the output surface which grew to catastrophic size. The Cu contaminants often were not completely ablated during testing. Stainless stecl spheres did not produce damage on the input surface.

Tungsten and gold reacted in a manner consistent with the other metals. Damage spread until a majority of the contaminant was ablated. An outline of the original contaminant was visible in the damage area, and debris was scattered about. 
Oxides behaved quite differently. $\mathrm{Wit}_{1} \mathrm{TiO}_{2}$, blistering and pits were seen. Input surface $\mathrm{TiO}_{2}$ contamination often lead to damage on the output surface in the form of a scald. $\mathrm{Al}_{2} \mathrm{O}_{3}$ damage sites showed an outline of the dot. Cracking of the glass was rather common. $\mathrm{ZrO}_{2}$ left a faint outlune of the contaminant with debris scattered farther away.

Carbon was the first organic studied. Its damage behavior was quite different than that observed with other malcrials. After irradiation, the damage was nearly transparent and was very thin and smouh Plastic and Teflon (Teflon particles were applied in a manner similar to Al shawngs) weren t noticeably affected by irradiation. With the exception of a small portion of the Teflon that was blown off during the 1 -on- 1 test, the appearance and size of these contammants did not change with irradiation.

Another major concern for NIF which was briefly considered is the effect of human contamination. Hair from hoth cats and humans was placed on the silica substrates by the method used for Al shavings described previously. The hair was then irradiated using the 1 -on-1,20-on- 1 and $S-0 n-1$ tests. For input surface contamination, cat hair was not affected by irradiation while human hair was ablated without damaging the fused silica.

\subsubsection{Input Surface Damage Size}

Different materials and contaminant sizes caused significant changes in damage behavior which was discussed previously in terms of damage morphology, but differences were also apparent in the final, stable size of damage sites. Contamination size was plotted against damage size to quantitatively measure growth after the 1-on-1, 20-on-1 and S-on-1 (600 shots at a $10 \mathrm{~Hz}$ repetition rate) tests. Figures 6,7 , and 8 
illustrate this by plotting input surface contamination size against damage size for a metal (stainless steel), an oxide $\left(\mathrm{TiO}_{2}\right)$, and an organic $(\mathrm{C})$, respectively.

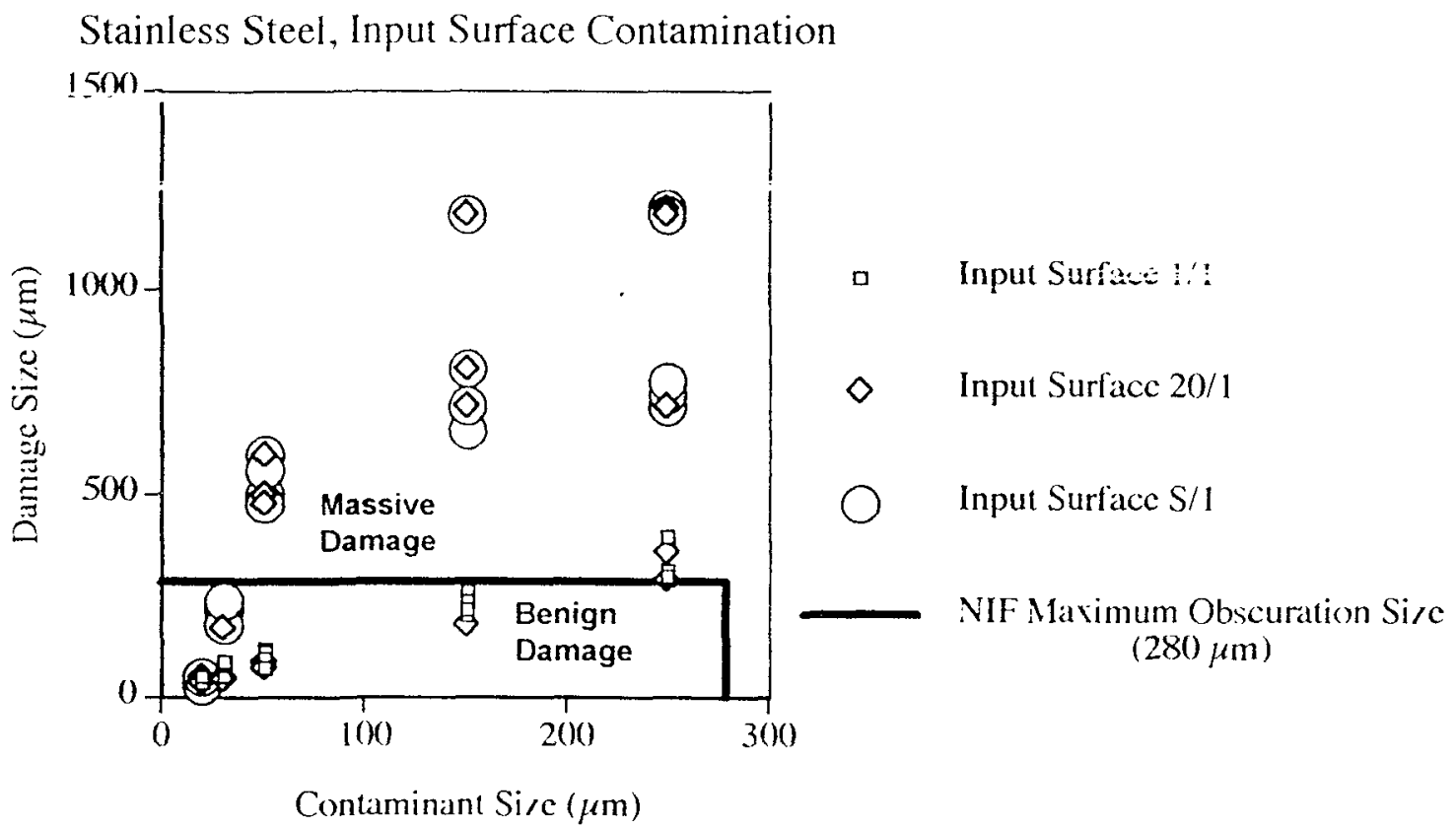

Fig. 6: Input surface damage size as a function of input surface contaminant size for sputtered stainless steel dots after 1-on-1, 20-on-1 and S-on-1 tests at $1064 \mathrm{~nm}$ and $40 \mathrm{~J} / \mathrm{cm}^{2}$ with an $8.6 \mathrm{~ns}$ pulselength. Stainless steel grows a great deal during repetitive illumination. Stainless steel serves as a good example of characteristic damage behavior for metals. 


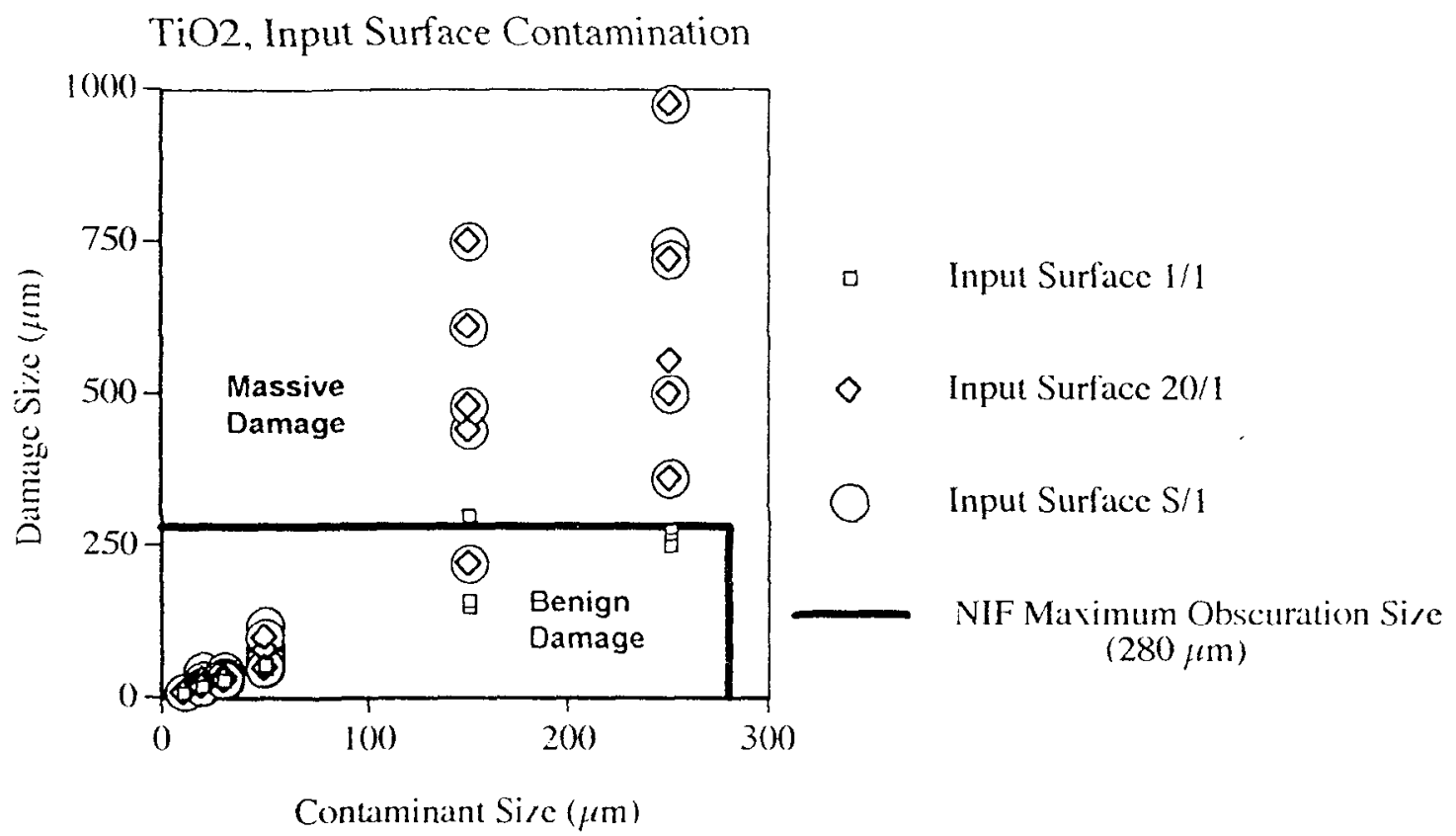

Fig. 7: Input surface damage size as a function of input surface contaminant size for sputtered $\mathrm{TiO}_{2}$ dots after 1-on-1. 20-on-1 and S-on-1 tests at $1064 \mathrm{~nm}$ and $40 \mathrm{~J} / \mathrm{cm}^{2}$ with an 8.6 ns pulselength. Damage continues to grow after the 1 -on- 1 test. $\mathrm{TiO}_{2}$ serves as a good example of characteristic damage behavior for oxides.

\section{Carbon, Input Surface Contamination}

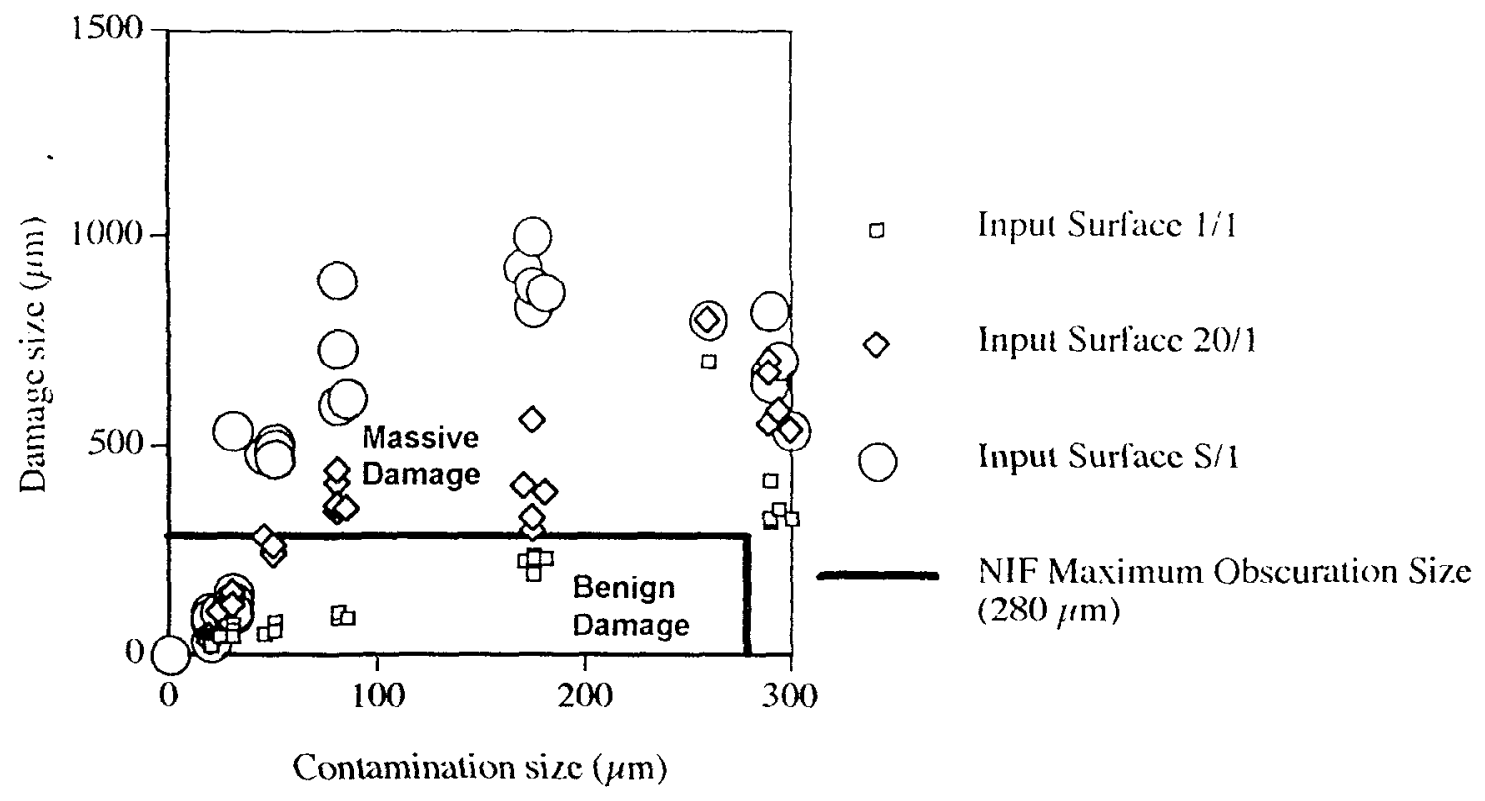

Fig. 8: Input surface damage size as a function of input surface contaminant size for sputtered C dots after 1-on-1, 20-on- 1 and S-on-1 tests at $1064 \mathrm{~nm}$ and $40 \mathrm{~J} / \mathrm{cm}^{2}$ with an 8.6ns pulselength. Damage spreads a great deal during repetitive illumination. No damage behavior trend was observed between organics. 
From these plots, scaling factors were determined. Final, stable damage size divided by initial contaminant sise gll es the scaling factor for an individual dot. By plotting Son-1 damage size against contaminant size, an average scaling factor for a given material on either the input or output surface $w$ as determined by overlaying a linear curve fit with $x$ and $y$ intercepts of zero onto the plot. The slope of the curve fit was equal to the average scaling factor. This procedure is illustrated in Section 3.2 .2 for output surface carbon contamination. It was repeated for all materials which have been subjected to a full study, and Figure 9 lists these scaling factors for both input and output surfaces. Catastrophic damage $w$ as neglected in these calculations because it was rare, and at this lime it is not possible to predict which contamination sites will lead to catastrophic damage. Materials which caused catastrophic damage are noted in the table. 


\section{Scaling Factors (95\% Confidence)}

\begin{tabular}{|c|c|c|}
\hline Material & $\begin{array}{l}\text { Input Surface } \\
\text { Scaling Factor }\end{array}$ & $\begin{array}{l}\text { Output Surface } \\
\text { Scaling Factor }\end{array}$ \\
\hline \multicolumn{3}{|l|}{ Metals } \\
\hline Aluminum & $2.7 \pm .65$ & $2.0 \pm .88$ \\
\hline Titanium & $4.4 \pm 1.34$ & Not Available \\
\hline Stainless Steel & $3.8 \pm 1.00$ & $1.1 \pm .09 *$ \\
\hline \multicolumn{3}{|l|}{ Oxides } \\
\hline $\mathrm{Al}_{2} \mathrm{O}_{3}$ & Not $\Lambda$ vailable & $1.2 \pm .17^{*}$ \\
\hline $\mathrm{TiO}_{2}$ & $2.8 \pm .58 *$ & $2.4 \pm .27$ \\
\hline $\mathrm{ZrO}_{2}$ & Not Available & $1.6 \pm .90^{*}$ \\
\hline \multicolumn{3}{|l|}{ Organics } \\
\hline Carbon & $3.5 \pm 1.16$ & $3.7 \pm .72$ \\
\hline Plastic & $1.0 \pm .00^{*}$ & $1.0 \pm .00$ \\
\hline
\end{tabular}

Fig. 9: Scaling factors are given for all contaminants which have been subjected to a full or nearly full study. The values were determined as illustrated in Figure 18. Catastrophic (unstable) damage was neglected in the calculation of scaling factors. The values are provided to $95 \%$ confidence.

Input surface damage aggravated by aluminum particles continued to grow during the 20-on-1 and S on-1 tests. Its scaling factor was about average for the tested materials at 2.7 \pm .65. Massive damage occurred from contaminants in the $100 \mu \mathrm{m}$ range. The $\mathrm{Al}$ 
shavings showed similar growth behavior to the sputtered dots. However, the shavings were usually thicker and of nonstandard mass which led to more scatter in the data.

Ti debris continued to spread a great deal upon repetitive illumination. Its final damage size at stability was significantly larger than aluminum's. Titanium's input

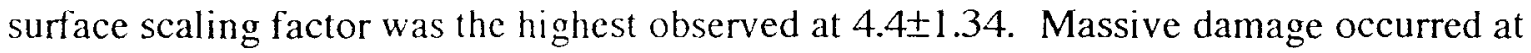
contaminants as small as $50 \mu \mathrm{m}$. but' the damage always reached stability, and no catastrophic failure occurred.

Copper damage grew at a very moderate rate. Enough data has not yet been collected to determine its scaling factor. For sputtered stainless steel, smaller dots grew very little after the 1-on-l test while the larger dots continued to spread a great deal. Its input surface scaling factor was quite high at $3.8 \pm 1.00$.

Overall, metals and oxides tended to create damage which was more likely to grow than damage from organics. Oxides appeared most likely to initiate catastrophic damage. Of these, enough data has only been collected for $\mathrm{TiO}_{2}$ to determine an input surface scaling factor of 2.8土.58. $\mathrm{TiO}_{2}$ caused backside damage at several locations, but it rarely grew to catastrophic. Both $\mathrm{Al}_{2} \mathrm{O}_{3}$ and $\mathrm{ZrO}_{2}$ caused catastrophic damage initiated on the output surface due to input surface contamination. Figure 10 shows the sort of damage which was classified as catastrophic. The glass actually cracked and was ablated. 


\section{Input Surface S/1 Damage Caused by $150 \mu m$ Input Surface Cu Contamination}

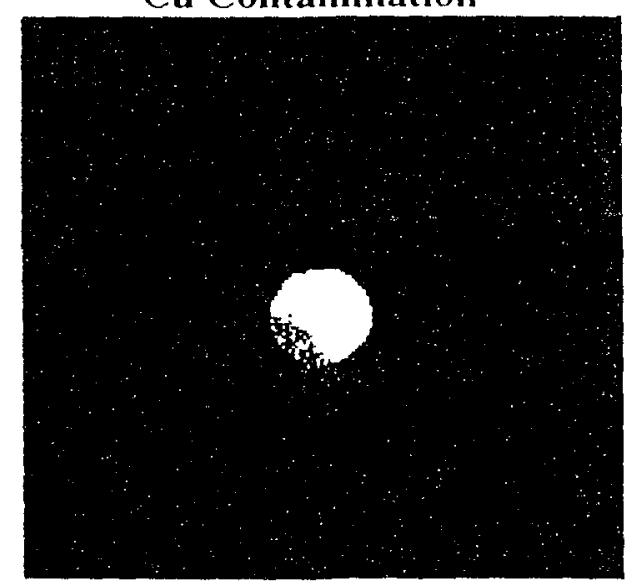

\author{
Output Surface S/1 Damage \\ Caused by $150 \mu m$ Input Surface \\ Cu Contamination
}

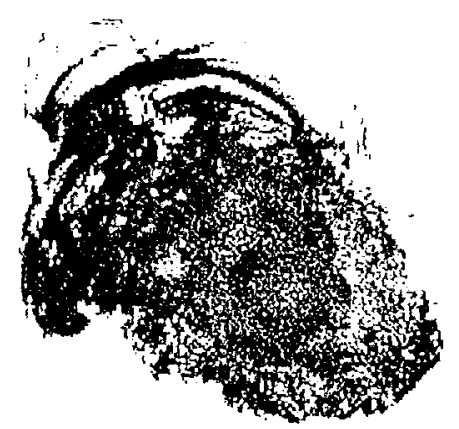

Fig. 10: Outpul surface damage can initiate trom inpul sulfice contamination This damage usually grows to catastrophic, olten during 20-on-1 testing. Here are shomn Nomarshi optical micrographs of the damage caused bs a $150 \mu \mathrm{m} \mathrm{Cu}$ contamination particle on the input surlace Both the inpul surlace and the output surlace are displayed atter Son-1 lesting. The inpul sulace damage is benign, but the output sultace damage has grow n to calastrophic It the substrate were illuminatedtuther, the cracking would spead and the optic would be destrosed. Input sut ace contaminationleading to output sulace damage is caused by light intensitication Catastrophic damage is uncommon at l()64nm and a fluence of $40 \mathrm{~J} / \mathrm{cm}^{2}$ but can initiateltom both inpul and oulput surfice contamination

For the organics, plastic wasn't affected in terms of damage size. It had a scaling factor of $1.0 \pm .00$ for the input surface. However, two $150 \mu \mathrm{m}$ plastic contamination particles caused backside damage which grew to catastrophic sizc. No damage was initiated by any of the other plastic contaminants.

Carbon's damage behavior was much different than that of other organics and other materials. No catastrophic damage was observed, but the damage grew a great deal during the 20-on-1 and S-on-1 tests. Its input surface scaling factor was $3.5 \pm 1.16$. Although particles as small as $30 \mu \mathrm{m}$ caused damage larger than the $280 \mu \mathrm{m}$ maximum obscuration size requirement for NIF which is classified as massive damage, it was 
unclear whether carbon damage would adversely affect the laser beam characteristics. The damage morphology. nearly transparent and very thin and smooth, was quite different from the type initiated by all other materials.

\subsection{Output Surface Contamination}

Damage only occurred at the contamination particle for output surface contamination. A plasma was often observed at the contaminant during the fïst shot. Subsequent shots rarely initiated plasmas, and damage was usually stable after the 1 -on- 1 test (damage did not grow) A ring pattern or outline was most common in the location where the contaminant had heen located. A majority of the contaminant was removed during the first shot and did not redeposit. A wave pattern was sometimes visible over the damaged area as seen in Figure 11.

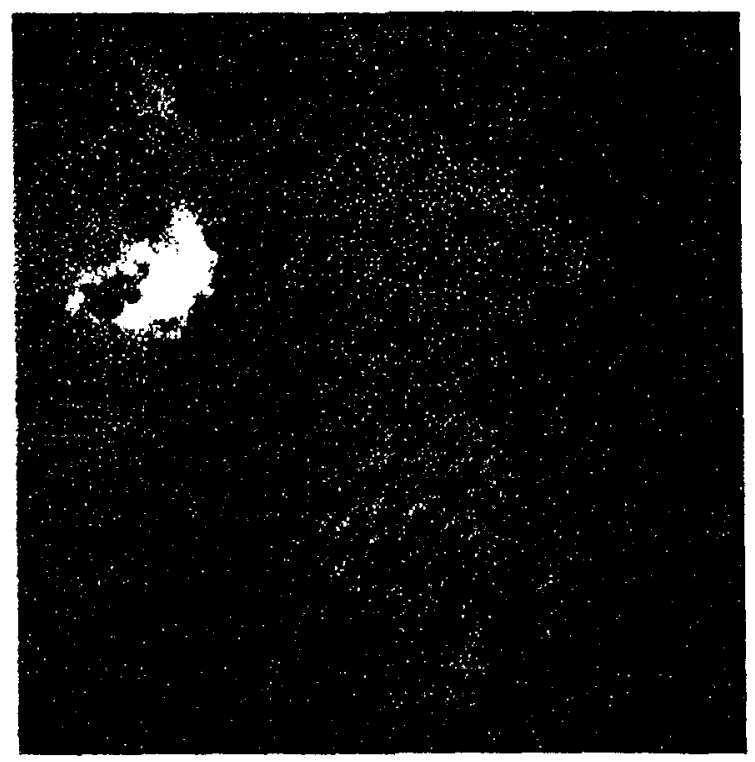

Fig. 11: A llalle paltern is sometimes risible or datmage initiated all output sultace contamination. Herc an optical micrograph of the $1 / 1$ damage initialed at at $250 \mu \mathrm{m}$ Al particle is presented. Ellorts all $\mathrm{c}$ currently underwat to understand "hat causes the $w$ al e patiem. 
Catastrophic damage occurred when the first shot was able to produce microcracks in the substrate. During further illumination, these cracks coupled with the light and continued to grow to catastrophic size. Atomic force microscopy showed that damage usually did not penetrate more than a feu hundred nanometers into the substrate surface.

\subsubsection{Output Surface Morphologies}

Figures 12-14 show the ypical damage morphologies of $150 \mu \mathrm{m}$ contamination particles on the output surface of the substrate for all materials tested before irradiation, after 1-on-1, 20-on-1, and $3-(11-1$ testing. As stated previously, the metal damage morphologies which have been characterized are $\mathrm{Al}, \mathrm{Ti}, \mathrm{Cu}, \mathrm{W}, \mathrm{Au}$, and stainless steel. Oxide morphologies examined are $\mathrm{Al}_{2} \mathrm{O}_{2}, \mathrm{TiO}_{2}$, and $\mathrm{ZHO}_{2}$. Organics which have been studied include carbon, plastic. Teflon, and hair. Much like input surface contamination, morphologies vary from material to material and for different contaminant sizes. Figure 15 shows the testing of all six Cu contaminant sizes on the output surface of the fused silica substrate. This represents $1 / 5$ of a complete output surface study of a contamination material. 


\section{$150 \mu m$ Output Surface Metal Contaminants Irradiated@1064nm, 40J/cm

Contaminant Before 1-on-1 20-on-1 S-on-1

Aluminum

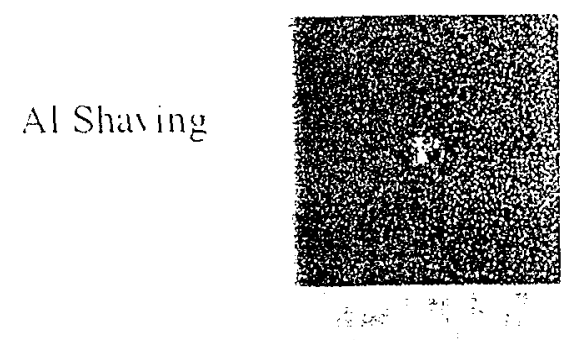

Tilanium

Copper

Stainless Stecl

Stainless Stcel

Spheres

Tungsten

Gold
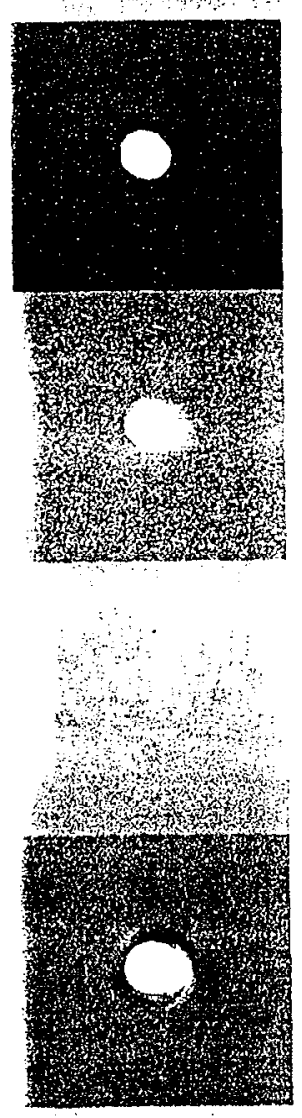
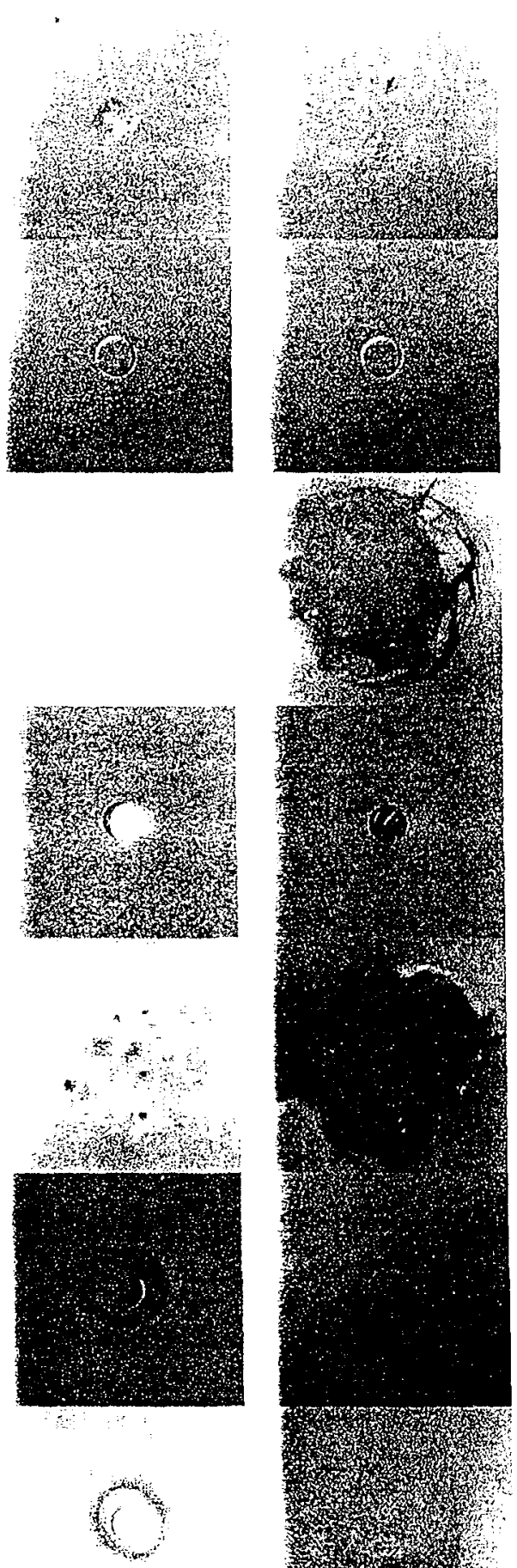

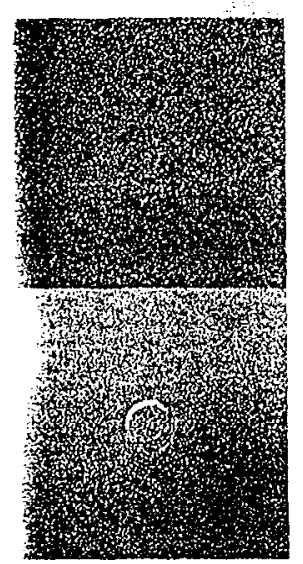

Calastrophic

Damage occurred during 2)-on-1 lesting

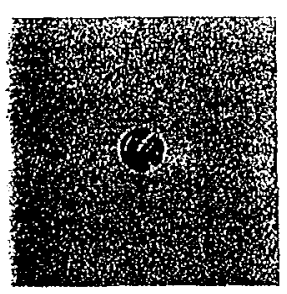

Catastrophic Damage occurred during 20-on-1 lesling

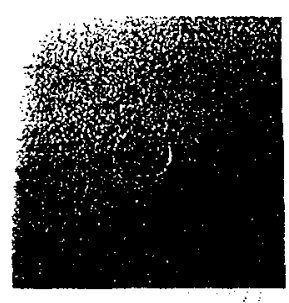


Fig. 12: Nomarski optical micrographs of the output surface damage morphologies initiated by $150 \mu \mathrm{m}$ contamination particles are displayed before irradiation; and after 1 on-1, 20-on-1, and S-on-1 testing for all metals tested. The morphologies observed were similar for different metals. An outline of the contamination particle is left on the surface of the fused silica. The damage grows very little unless serious pitting of the silica occurred during 1 -on-1 testing. This pitting will grow to catastrophic proportions as seen here in $\mathrm{Cu}$ and the stainless steel spheres. 


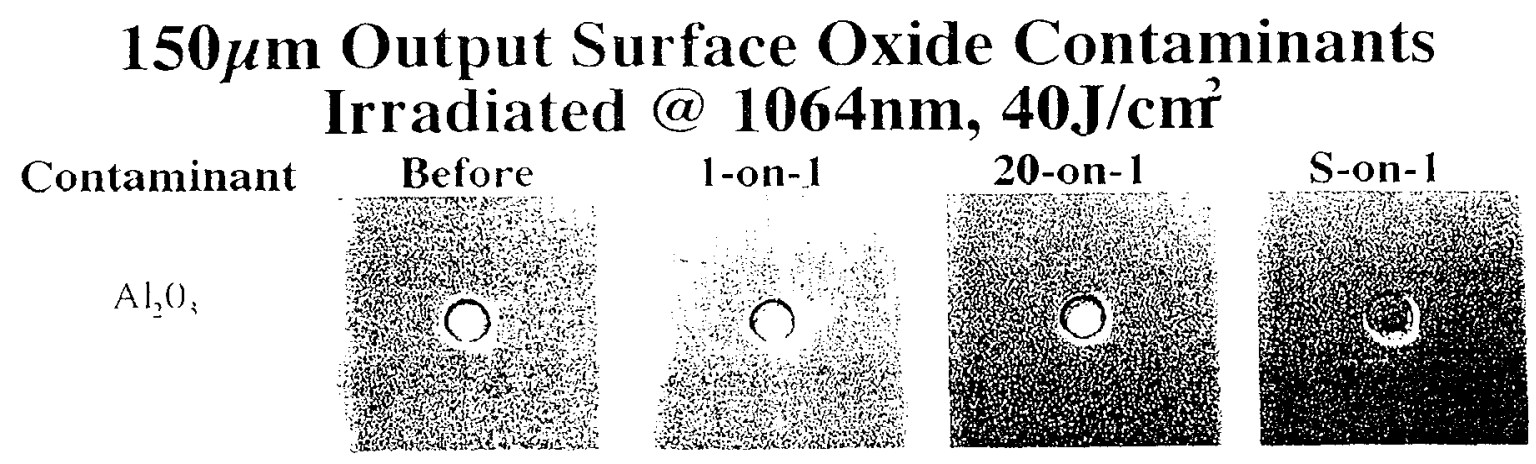

$\mathrm{TiO}_{2}$

$\mathrm{ZrO}_{2}$

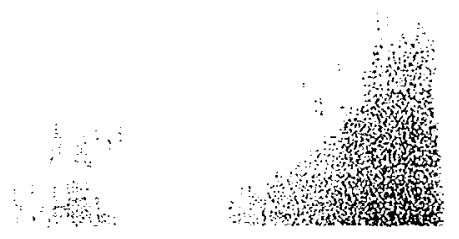

Fig. 13: Nomarski optical micrographs of the output surface damage morphologies initiated by $150 \mu \mathrm{m}$ contamination particles are displayed before irradiation; and after 1 on-1,20-on-1, and S-on-1 testing for all oxides tested. The morphologies observed were similar for different oxides. The damage initiated is usually benign unless catastrophic damage occurs which is common among oxides. 


\section{$150 \mu \mathrm{m}$ Output Surface Organic Contaminants Irradiated@1064nm,40J/cm² \\ Contaminant \\ Before \\ 1-on-1 \\ S-on-1}

Cillbon
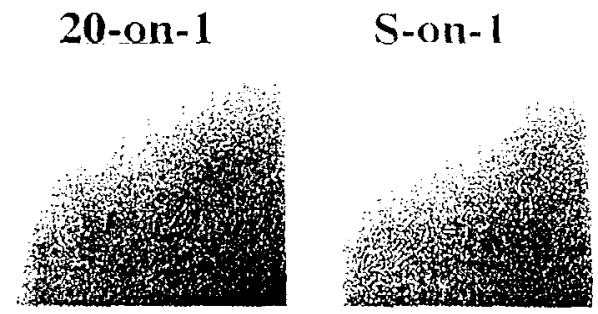

Plastic

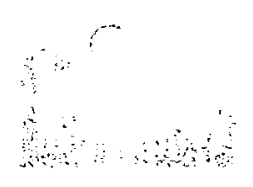

Tellon

Cal Hair
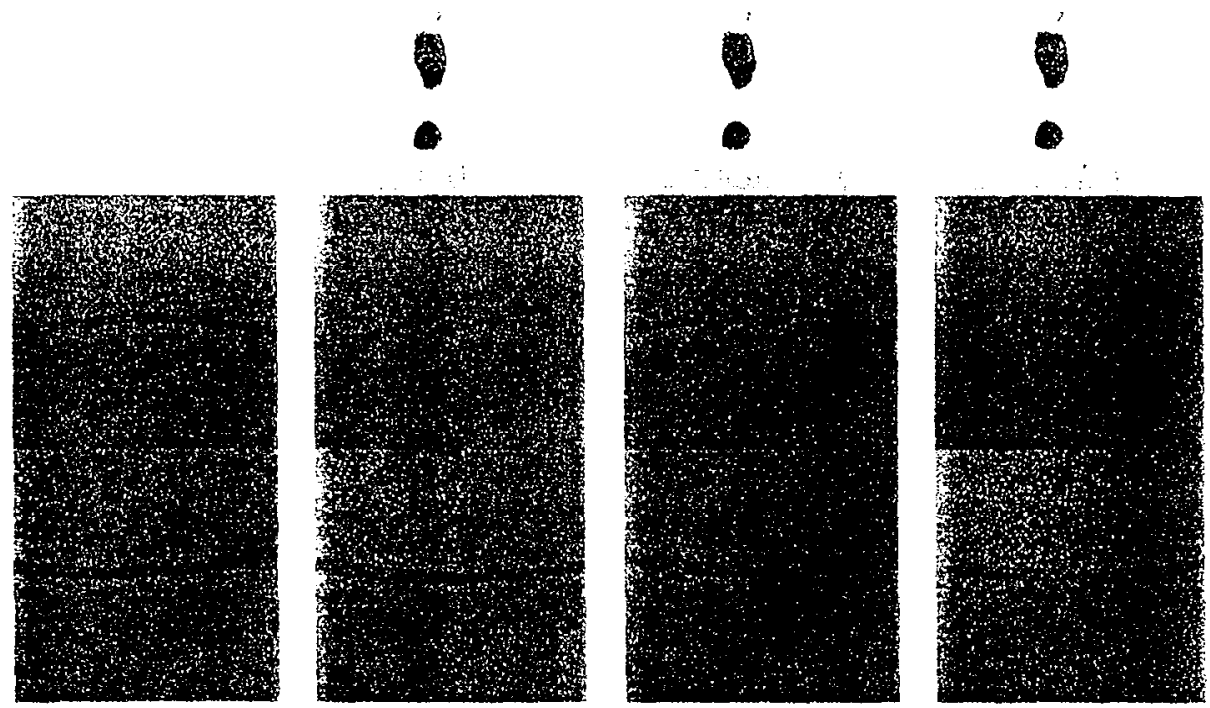

Fig. 14: Nomarski optical micrographs of the output surface damage morphologies initiated by $150 \mu \mathrm{m}$ contamination particles are displayed before irradiation: and after 1 on-1, 20-on-1, and S-on-1 testing for all organics tested. The morphologies observed were dissimilar for different organics. Input and output surface organic contamination initiate similar damage. 


\section{Output Surface Copper Contaminants Irradiated@1064nm, 40J/ $\mathrm{cm}^{2}$}

Size $(\mu \mathrm{m})$

1)

I)

3()

50

150

250
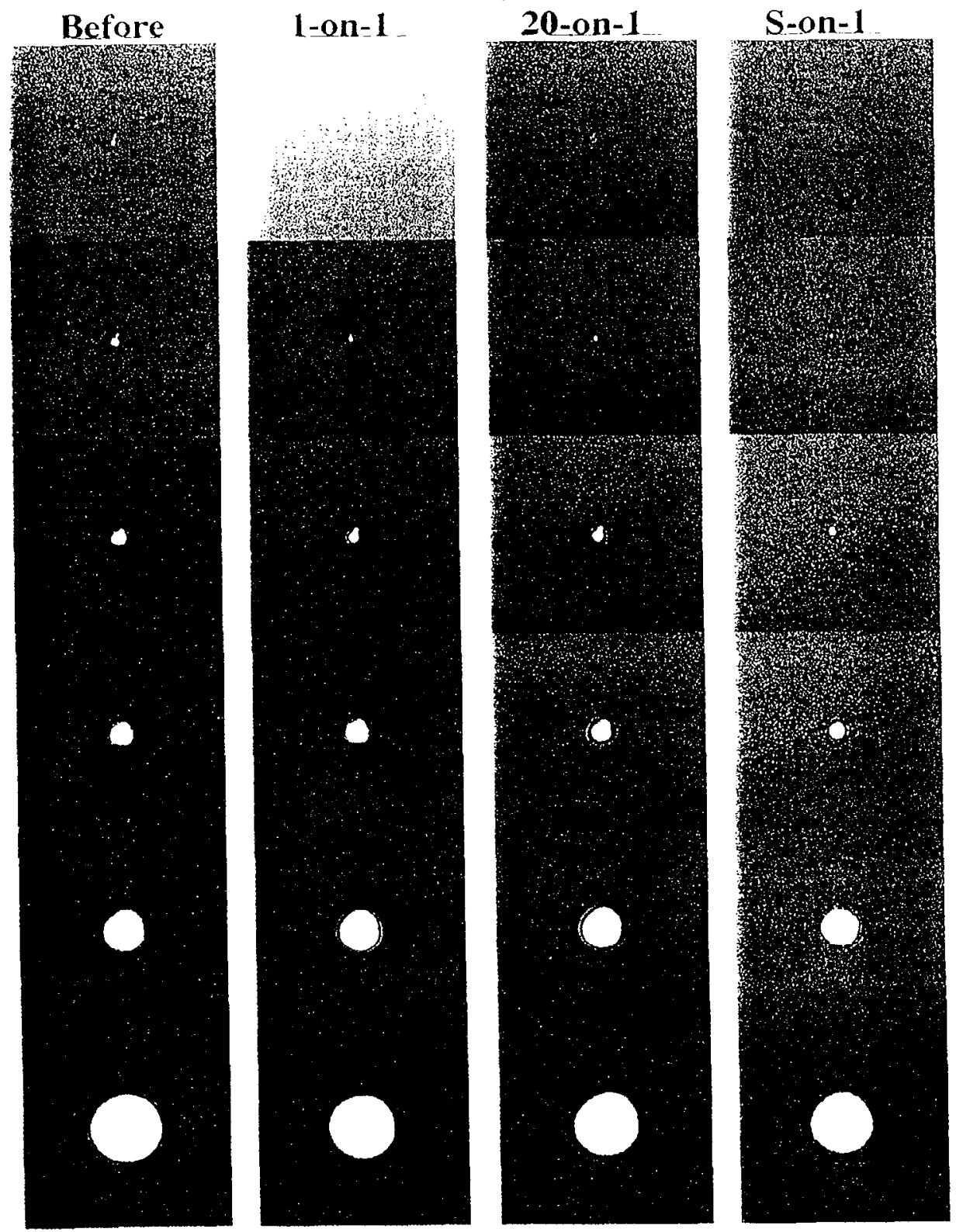

Fig. 15: Nomarski optical micrographs of the 6 sputtered dot sizes for output surface $\mathrm{Cu}$ contamination are shown before irradiation and after 1-on-1, 20-on-1, and S-on-1 testing ( 600 shots at a $10 \mathrm{~Hz}$ repetition rate). Output surface damage does not grow during repetitive illumination. The characteristic output surface damage morphology consists of an outline of the contaminant. Pitting is often observed along the edge of the outline. Copper contamination initiates relatively benign damage as compared to other materials. This figure represents $1 / 5$ of a full output surface contamination study. 
Again, although the initial findings for Al contamination have already been reported elsewhere [22], the information is briefly presented here in the context of other contaminants irradiated at $1064 \mathrm{~nm}$. For output surface contamination, the Al dot was usually ablated on the first shot. An outline or ring was seen where the dot was located, and a wave pattern was sometimes visible over the outline. The Al shavings behaved much like the dots, although catastrophic damage did occur during the Al shavings testing.

Titanium on the output surface often caused cracking in the larger dots and left an outline in the smaller dots. Copper's damage morphology usually consisted of an outline of the contaminant. The contaminant was not completely ablated during irradiation. Catastrophic damage was also observed. Sputtered stainless steel contaminants left a scald in the location of the dot. The material was ablated during the first shot. The stainless steel spheres were sometimes able to cause cracking in the silica which led to catastrophic damage. Tungsten and gold initiated benign damage which left a faint outline of the contaminant and did not grow during repetitive illumination.

The oxides all exhibited similar output surface behavior and left an outline of the contamination particle. $\mathrm{Al}_{2} \mathrm{O}_{3}$ and $\mathrm{ZrO}_{2}$ also initiated pits or cracking. $\mathrm{TiO}_{2}$ damage left significantly more debris than the other oxides.

The organics damaged in a similar fashion on the output surface to the manner in which they damaged on the input surface. Carbon-initiated damage was nearly transparent, thin, and smooth. Plastic and Teflon did not react with the beam. The contaminant was not ablated, nor was damage observed. The cat hair and human hair 
damage morphologies changed. On the output surface, human hair did not damage while cat hair was partially ablated

\subsubsection{Output Surface Damage Size}

As explained in Section 3 1.2. damage size can be plotted against initial contaminant size, and scaling factors can be determined which predict the size of damage expected from a particle of known size and material. Figures 16, 17, and 18 illustrate this idea by plotting output surface contamination size against output surface damage size for a metal (Al shavings), an oxide ( $\mathrm{TiO}_{2}$ ), and an organic $(\mathrm{C})$, respectively.

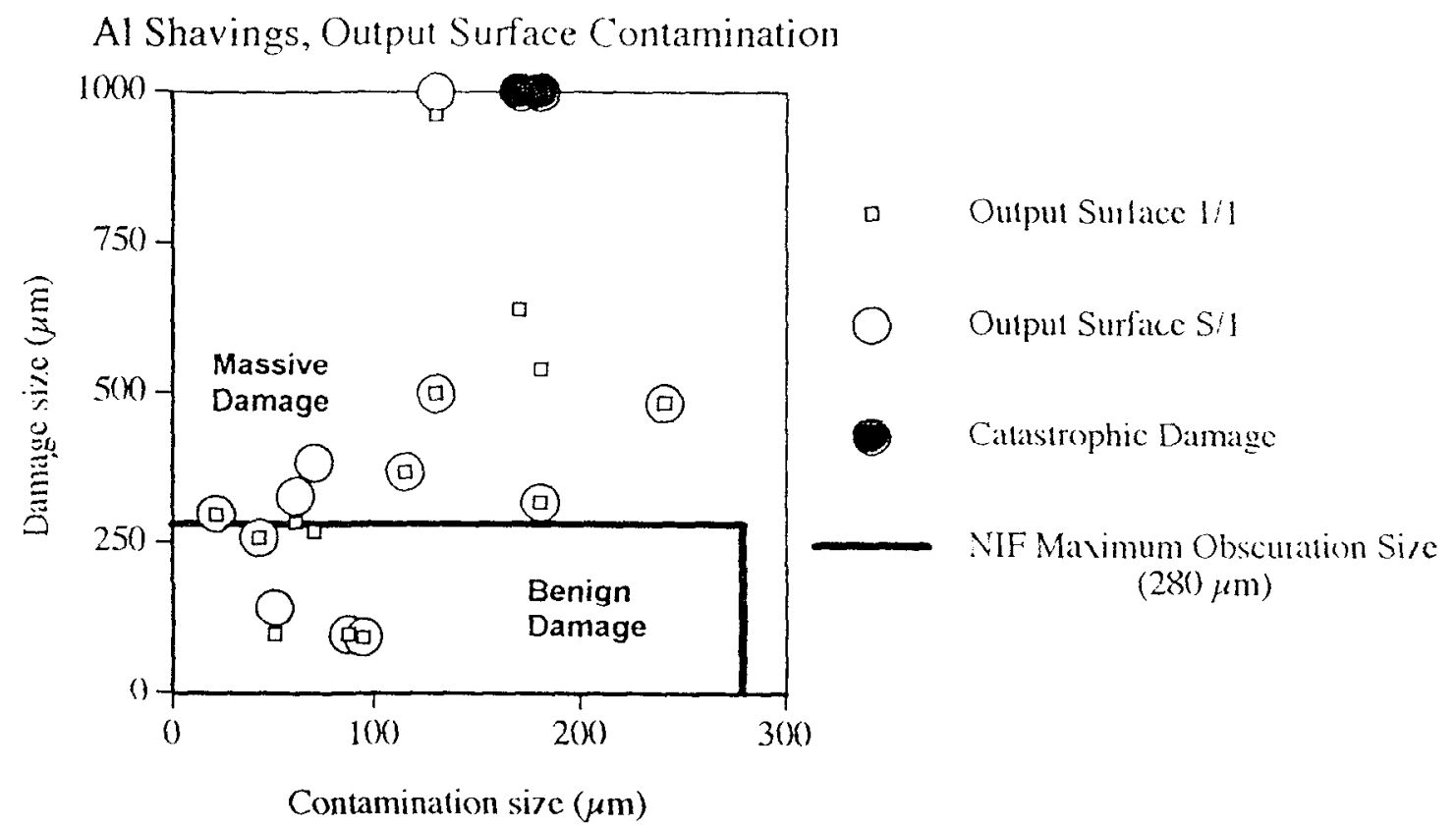

Fig. 16: Output surface damage size as a function of output surface contaminant size for Al shavings after 1 on 1 and $S$-on- 1 tests at $1064 \mathrm{~nm}$ and $40 \mathrm{~J} / \mathrm{cm}^{2}$ with an $8.6 \mathrm{~ns}$ pulselength. Output surface damage doesn't grow after 1-on-1 testing. Catastrophic damage can occur. Al shaving damage grew more than other metals on the output surface due to the increased mass of the particles. Sputtering allows better control over the mass of particles. 


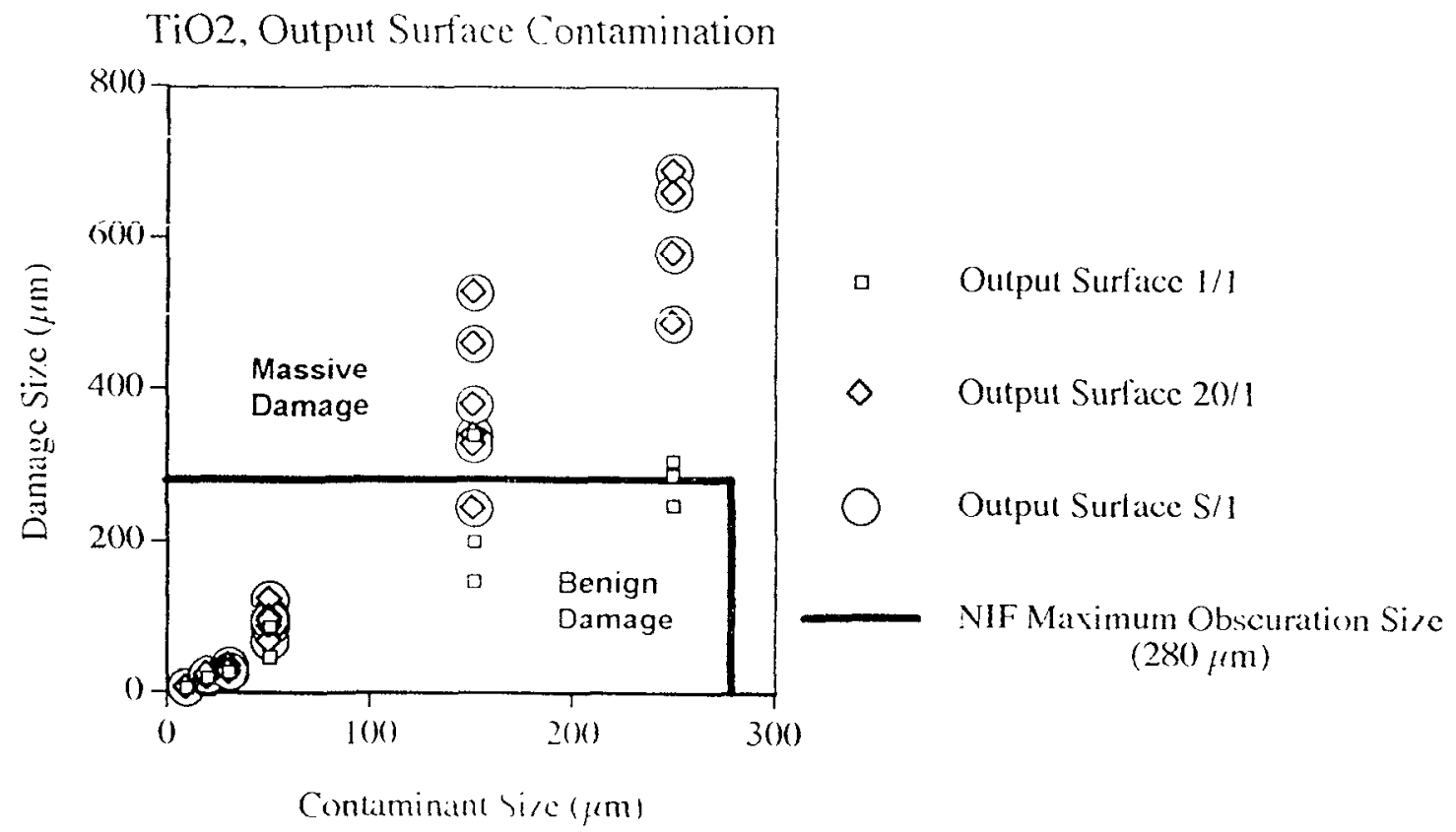

Fig. 17: Output surface damage size as a function of output surface contaminant size for sputtered $\mathrm{TiO}_{2}$ dots after 1-on-1.20-on-1 and S-on-l tests at $1064 \mathrm{~nm}$ and $40 \mathrm{~J} / \mathrm{cm}^{2}$ with an 8.6 ns pulselength. Damage continues to grow after the 1 -on-1 test. Output surface damage grows less than input surface damage. TiO, serves as a good example of characteristic damage behavior for oxides.

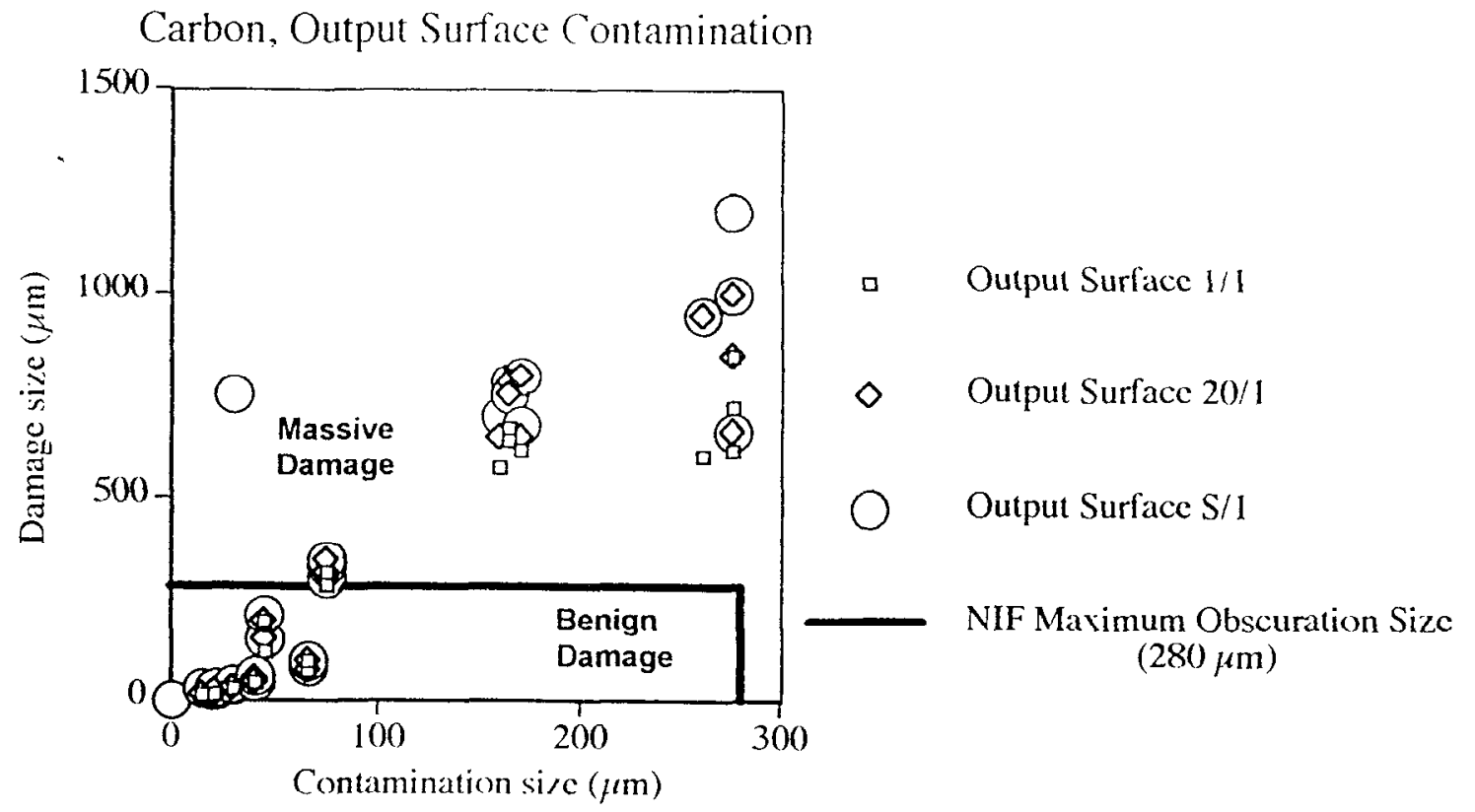

Fig. 18: Output surface damage size as a function of output surface contaminant size for sputtered C dots after 1-on-1,20-on-1 and S-on-1 tests at $1064 \mathrm{~nm}$ and $40 \mathrm{~J} / \mathrm{cm}^{2}$ with an 8.6 ns pulselength. Damage spread more for output surface contanination than for input surface contamination. No damage behavior trend was observed between organics. 
From these and similar plots. scaling factors were determined for all materials subjected to a full study (see Figure 9). Figure 19 illustrates the procedure for output surface carbon contamination.

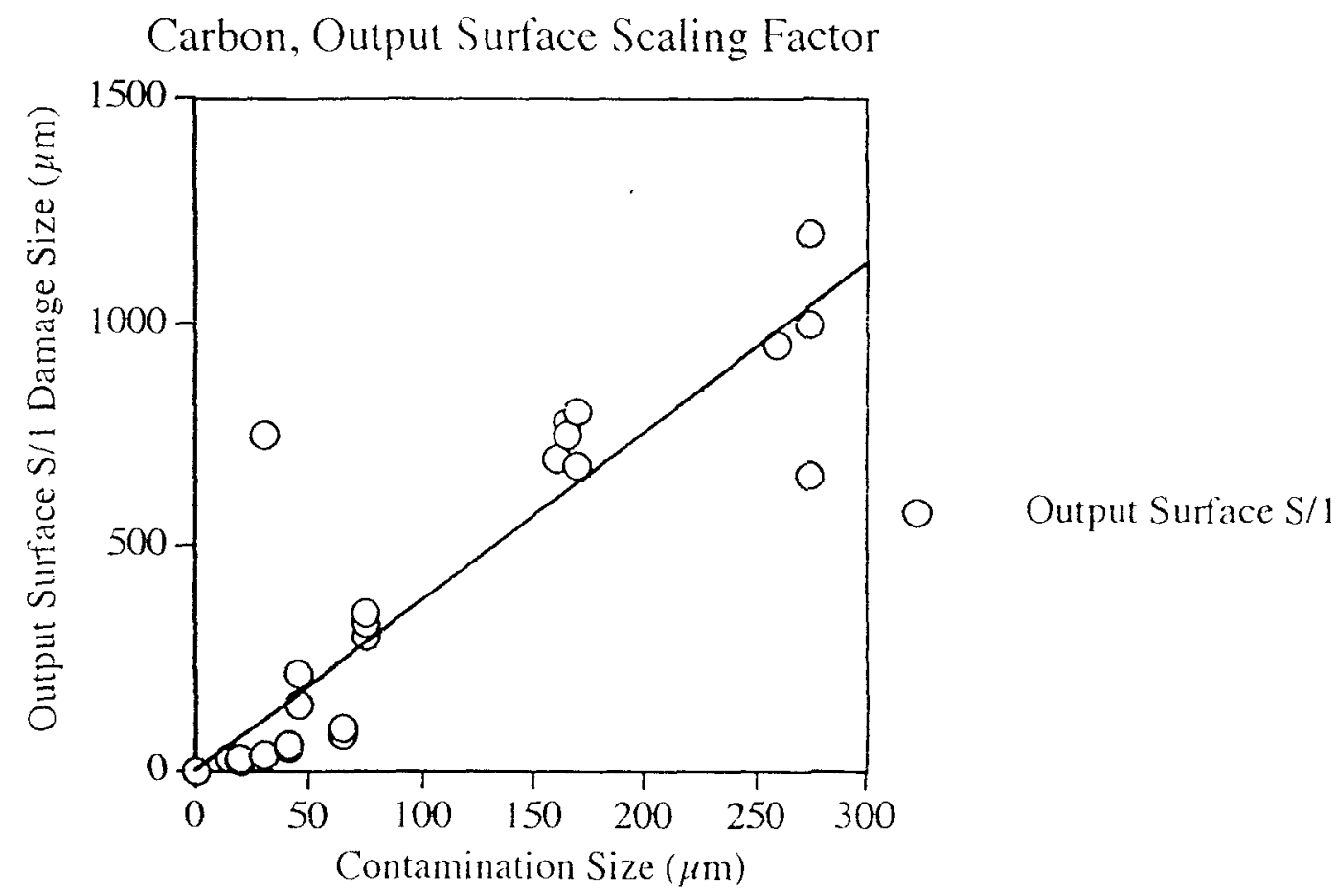

Fig. 19: Scaling factors can be determined that predict the final damage size which a contaminant will initiate. The process is shown here for carbon contamination on the output surface. S-on-1 damage size is plotted against contaminant size. A linear curve fit with $x$ and $y$ intercepts of zero is overlaid onto the graph. The slope of the curve fit is equal to the average scaling factor. For output surface $C$, the curve fit has an equation which is approximately $y=3.8 x$. This yields a slope of 3.8 which is the average scaling factor. Error analysis then characterizes the quality of the fit and establishes confidence intervals. Output surface carbon has an interval of \pm .72 to $95 \%$ confidence. Catastrophic (unstable) damage was neglected in the calculation of scaling factors.

Output surface Al contamination usually did not grow after the first shot. Massive damage was mainly observed in the 150 and $250 \mu \mathrm{m}$ contaminants. Al shavings damage was consistent with the sputtered dots. The sputtered Al dots had a scaling factor of $2.0 \pm .88$ 
Titanium output surface damage grew to catastrophic proportions on several occasions. When this did not occur. damage was benion. Enough reliable data has not been collected to determine its scaling factor. Sputtered stainless steel blistered during the first shot, and the material was ablated. Very little growth occurred; its scaling factor was $1.1 \pm .09$ for the output surface. Enough data is not currently available to determine scaling factors for stainless stcel spheres. tungsten. and gold.

Again, the oxides were able to cause serious damage. $\mathrm{TiO}_{2}$ never went catastrophic, but it left more debris than is common for output surface contaminants and scaled on average to $2.4 \pm .27$ times its initial size. $\mathrm{Al}_{2} \mathrm{O}_{;}$and $\mathrm{ZrO}_{2}$ had lower scaling factors at $1.2 \pm .12$ and $1.6 \pm 90$, respectively, but the factors neglect the numerous catastrophic damage sites which they both initiated.

The output surface organics exhibited damage sizes similar to those seen with input surface organic contamination. Carbon was the only material with a larger output surface scaling factor than input of $3.7 \pm .72$. Even though carbon damage grew to massive sizes very quickly, its characteristic damage morphology was quite different than other materials. The effect of damage on beam characteristics is currently being studied by interference microscopy measurements of phase shifts, and it's unclear at this time whether carbon damage is detrimental.

Plastic showed no reaction to irradiation and has a scaling factor of 1.0 1.00 . A full study has not been conducted on Teflon, cat hair, and human hair. 


\section{DISCUSSION}

This section discusses the process used to quantify experimental error in the scaling factors (4.1) and examines the mechanism of catastrophic damage (4.2).

\subsection{Uncertainty Analysis}

Error in the scalıng fictors was induced from both bias uncertainty of the experimental measurements and precision uncertainty from fluctuation of stable damage size around a mean value However, bias uncertainty was negligible in comparison to precision uncertainty. Precision uncertainty was determined to $95 \%$ confidence as discussed in Appendix $G$ of Reference 24.

Since the precision error in final damage sizes was significantly larger than that in the initial contaminant sizes. contaminant size was plotted against damage size and a line of equation $y=a x \cdot h$ was calculated through the data. The intercept $a$ was set to zero since contaminants of no size obviously do not grow. The slope $h$ was equal to the scaling factor for the contaminant (see Fig. 19). Least-squares curve fitting is escentially a method of averaging out the $y$ precision error in data that satisfy an underlying linear relationship. Error analysis was used to characterize the quality of the fit.

Confidence intervals for the slope were determined under the assumption that the precision error in $y_{i}$, the experimentally measured damage size, satisfied the norma! distribution. The true slope (scaling factor) then lies within the $\%$ confidence interval given by:

$$
b \pm t_{x 2 y} \frac{s_{:}}{S_{x x}}(c \%)
$$


where $t_{w / 2, v}$ is the $t$-statistic with $v=n-2$ degrees of freedom ( $n$ is the sample size) at an $\alpha=(1-c)$ level of significance. $s_{3}$ is the standard error of the damage size about the curve fit as determined by

$$
,=\left(\frac{1}{(n-2)} \sum_{i=1}^{n}\left[y_{i}-y\left(x_{i}\right)\right]^{2}\right)^{12}
$$

This approximates the standard deviation of the precision error in $y_{i}$. The quantity $x_{i}$ is the experimentally measured contammant size, and $y\left(x_{j}\right)$ is the corresponding damage size calculated from the equation of the curve fit. $S_{x x}$ is the total squared variation of the $x$ data (precision error and the etraight-line variation of $x$ with $y$ ) defined by:

$$
S_{n}^{2}=\sum_{i=1}^{n} x_{i}^{2}-\frac{1}{n}\left(\sum_{i=1}^{n} x_{i}\right)^{2}
$$

The $95 \%$ confidence intervals are given in Figure 9.

\subsection{Catastrophic Damage}

The most interesting and destructive behavior encountered in the study was catastrophic damage. Modeling efforts are underway at LLNL to determine the mechanism of such damage in order to limit its occurrence. Research Scientist David Eder points to three major factors that his modeling group believes contribute to it.

The first two mechanisms cause output surface damage from output surface contamination. When the laser pulse makes contact with the contaminant on the back surface, the energy is absorbed by the contaminant at the interface between it and the silica substrate. This often melts and vaporizes the contaminant. At this point, the 
temperature mismatch at the interface is sometimes enough to thermally shock and crack the substrate.

The damage can also be caused by the interface pressure mismatch. When the contaminant vaporizes at the interface, the pressure locally increases and puts the contaminant and the substrate in compression at the interface. As the energy spreads through the contaminant. it continues to vaporize and the pressure is released through the top or sides of the contammant. However, the larger the diameter and thickness of the contaminant, the longer it takes for the pressure to be released. The pressure puts the surface of the substrate at the interface in compression. This in turn applies smail tensile forces into the silica which, if not alleviated quickly. fracture the surface and lead to catastrophic failure of the substrate.

The third mechanism can cause catastrophic output surface damage due to both input and output surface contamination. When the contaminant absorbs the laser energy and a plasma is observed, UV radiation is released which is absorbed by the substrate. Subsequent laser puises do not simply pass through the silica as before but couple with the absorbed radiation to crack the output surface. More intense plasmas are observed with larger contaminant sizes for a given material. Plasma intensity is based on the mass of the contaminant which explains why larger particles cause catastrophic damage more often. 


\section{CONCLUSIONS}

A study to examine the effects of contamination on optics in high fluence lasers such as NIF and LMJ is underway. The initial results observed for contaminants on both the input and output surfaces of fused silica irradiated at $1064 \mathrm{~nm}$ are presented herein. An artificial contamination method was used to contaminate the optics. This allowed rapid data collection. The results were very reproducible and systematic.

The contamination method proved to approximate the conditions encountered on large scale laser systems. Al shavings which closer approximate real contaminants produced data consistent with that collected from sputtered $\mathrm{Al}$ dots.

Input surface contamination tends to cause a plasma during the 1 -on-1 test and continues to spread during repetitive illumination. The surface usually appears burnt with craters or pits in the location of the original contaminant, and debris is scattered about. Organics behave quite differently than other materials. Carbon creates a large, nearly transparent, smooth damage area. Plastic and Teflon are not affected by irradiation. Input surface contamination can cause output surface damage through light intensification. A plasma is often observed on the output surface as well as the input surface during this phenomenon. The occurrence of backside damage usually leads to catastrophic damage. This is rare and is almost exclusively encountered in larger dots $(>100 \mu \mathrm{m})$. Oxides seem to lead to catastrophic failure most often.

Output surface contamination normally causes a plasma during the first shot in which most of the contaminant is ablated. Further illumination generally has little affect. The damage morphology is usually an outline where the contaminant had been located and pitting at the rim. Very little debris is seen scattered around. A fine wave pattern is 
sometimes observed on the surface. Again, organics behave differently. Their behavior is very similar for both input and output surfaces. Catastrophic damage can occur from output surface contamination if microcracking was caused in the substrate during the first sinot. Again, for the materals tested. oxides tend to cause catastrophic damage from output surface contamination most regularly.

The damage morphologs of a material is very reproducible from particle to particle for the same fluence and particle size. Morphologies are quite different for particles on the input versus output surtice. Different morphologies are also observed for different materials.

This study shows that contamination particles of a critical size determined by material and illumination surtace will be unacceptable and must be avoided on high power lasers as they will negatively impact performance and perhaps lead to catastrophic failure of optics in the beam line. Many other variables must be addressed before contamination effects are fully understood and methods of accounting for them are developed. Scaling factors provide a systematic way of predicting damage size from initial contaminant size. material. and fluence. These factors in turn can be used to set first order cleanliness standards for NIF optics. The standards must be arrived at in such a way that, with a factor of safety, predicted damage size from allowable particle sizes and materials remains benign $(<280 \mu \mathrm{m})$. 


\section{FUTUIRE}

This article reports the initial findings of a study designed to characterize the effects of contamination in all the multitude of ways in which it could affect the performance of optics in high fluence lasers. cspecrally the National Ignition Facility. The study to date has established a reliable, reproducible, and systematic method of collecting data. The effects of many different contaminants on bare fused silica irradiated at $1064 \mathrm{~nm}$ have been characterized. Many ksues still need to be addressed and are currently being studied or are slated for funce work. These are discussed below.

\subsection{Ramping Studies}

Contamination effects at a thuence of $40 \mathrm{~J} / \mathrm{cm}^{2}$ are relatively well characterized and understood. Experimentation at other fluences is now being performed to determine scaling factors at any fluence by dividing contaminant size by S-on-1 damage size and plotting versus fluence. This $\mathbf{w}$ ill allow prediction of final damage size for contaminants of any size or material at any fluence.

\section{$6.22 \mu \mathrm{m}$ Dots}

The effect of particle mass is important as seen in the results from the Al shaving study, but more work is needed to quantify these effects. The first step is to study a fused silica substrate with $2 \mu \mathrm{m}$ thick sputtered dots and compare results to those obtained from $1 \mu \mathrm{m}$ thick dots. 


\subsection{NIF Optics}

Contamination effects on fused silica have been studied, but work must be done on the other types of optics which will be used in NIF. These include phosphate glass, mirtors, polarizers, AR-coated fused silica, and KDP crystal. Optics of different thickness also need to be examined.

\section{$6.4355 \mathrm{~nm}$ Laser Illumination}

The NIF beam line will run at both $1064 \mathrm{~nm}$ and $355 \mathrm{~nm}$. All studies conducted at $1064 \mathrm{~nm}$ must be repeated at $355 \mathrm{~nm}$. Initial results show that damage is much more severe at $355 \mathrm{~nm}[22-23]$.

\subsection{Modeling and the Mechanism of Catastrophic Damage}

A fuller understanding must be gained of the physical processes which lead to damage. Of pertinent interest is the mechanism of catastrophic failure, and modeling efforts are concentrating on this phenomenon. For input surface contamination. initial work points to UV radiation caused by plasmas which is absorbed by the glass and couples with the incoming laser light which cracks the glass. Output surface contaminants cause a shock wave brought about by a pressure or temperature gradient at the substrate/contaminant interface which induces cracking of the silica $[15,19-21]$. More work must be done to verify that these are the main causes of the damage and to establish statistical probability about when catastrophic damage will occur. 


\section{ACKNOWLEDGMENTS}

This work was performed under the auspices of the U.S. Department of Energy by Lawrence Livermore National Laboratory under Contract W-7405-Fng-48. The study was conducted by F. Y. Génin, K. Michlitsch, Mark Kozlowski, Jim Yoshiyama, and Jim Furr. The researchers wish to acknowledge Peter Krulevitch, Lan Nguyen, and Craig Alford for the production of silicon nitride membrane masks and contamination deposits. 


\section{REFERENCES}

1. R. P. Gonzales and D Milam. "Evolution during multiple-shot irradiation of uniage sumounding isolated platinum inclusions in phosphate laser glasses", LaserInduced Damage in (Iptcal 1 Materials, NBS SP 746, 128 (1985).

2. M. R. Kozlowski, R Chow, and I. M. Thomas, "Optical coatings for high power laser applications", Handbook of Laser Science and Technology, Supplement 2: Optical Materials, ed. M. J. Weber. (RC. Press. 767, (1995).

3. M. D. Miller, R Chou. and G. E. Loomis, "Electrostatic reduction of particulates for laser-resistant hafnia coatings". Iuser-Induced Damage in Optical Materials, SPIE 2114, 426 (1993).

4. I. A. Fersman, L. D. Khazov" "The effect of surface cleanliness of optical elements on their radiation resistance". Sover . Journal of Optical Technology' 37, 627 (1971).

5. G. R. Wirtenson. "High fluence effects on optics in the Argus and Shiva laser chains", Optical Engineermy 18. 574 (1979).

6. B. E. Newnam, “Optical materials for high-power lasers: recent achievements", Laser Focus 18, 53 (1992).

7. J. B. Heaney, H. Herıg, J F Osantowski, “Auger spectroscopic examination of $\mathrm{MgF}_{2}$-coated Al mirrors before and after UV irradiation", Applied Optics 16, 1886 (1977).

8. S. Guch, Jr. and F. E. Hovis, "Beyond perfection: The need for understanding contamination effects on real-world optics", Laser-Induced Damage in Optical Materials, SPIE 2114, 505(1994).

9. M. A. Acharekar, " Infra-red absorption spectroscopy of Nd:YAG and Nd:GSGG surface contaminants". Luser-Induced Damage in Optical Materials, NBSSPP 746, 170 (1985).

10. K. Mann, B. Wolff-Rottke, and F. Müller, "Removal of dust particles from metal mirror surfaces by eximer laser radiation", Laser-Induced Damage in ()ptical Materials, SPIE 2428, 226 (1994).

11. D. Jollay, "Manufacturing experience in reducing environmental induced failures of laser diodes", Laser-Induced Damage in Optical Materials, SPIE 2714, 679 (1995).

12. C. E. Geosling, "Clean cavity contamination in gas lasers", SPIE 2714, 689 (1995).

13. G. A. Harvey, T. H. Chyba, and M. C. Cimolino, "Cleanliness and damage measurements of optics in atmospheric sensing high energy lasers", Laser-Induced Damage in Optical Materials, SPIE 2714, 696 (1995).

14. F. E. Hovis, B. A. Sherperd, C. T. Radcliffe, A. L. Bailey, and W. T. Boswell, "Optical damage at the part per million level: The role of trace contamination in laser induced optical damage", Laser-Induced Damage in Optical Materials, SPIE 2428, 72 (1994).

15. F. E. Hovis, B. Sherperd, C. T. Radcliffe, and H. A. Maliborski, "Mechanisms of contamination induced optical damage in pulse lasers", Laser-Induced Damage in Optical Materials, SPIE 2428, 72 (1994).

16. F. E. Hovis, B. A. Sherperd, C. T. Radcliffe, and H. A. Maliborski, "Contamination damage in pulse $1 \mu \mathrm{m}$ lasers", Luser-Induced Damage in Optical Materials, SPIE 2714, 707 (1995). 
17. J. T. Hunt. K. R. Manes, and P. A. Renard. Applied Optics 32. 5973 (1993).

18. A.J. Morgan, F. Ranner, F.P DeMarco, R.P. Gonzales, M. R. Kozlowskik, and M. C. Staggs, "Expanded damage test facilities at LLNL". Laser-Indluced Damage in

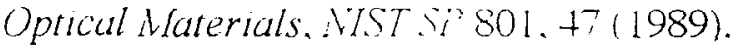

19. M. D. Feit. A II Rubenchik. D. R. Faux. R. A. Riddle. A. Shapiro, D. C. Eder, B. M. Penetrante, D. Milam, F Y. Génin, and M. R. Kozlowski, "Modeling of Laser Damage Initiated by Surface Contamination", Solid State Lasers for Application to Inertial Confinement Fusun. Paris. France, in press (1996).

20. M. D. Feit, A. M Rubenchik. D. R. Faux, R. A. Riddle, A. Shapiro, D. C. Eder, B. M. Penetrante, D. Milam. F Y Génin, and M. R. Kozlowski, "Modeling of Laser Damage Initiated by Surface Contamination", Laser-Induced Dumage in Optical Materials, SPIE 2966, 417(1996).

21. M. D. Feit, A. M Rubenchik, "Laser Intensity Modulation by Nonabsorbing Defects", Laser-Induced I amuge in Optical Materials, SPIE 2966, 475 (1996).

22. F. Y. Génin, K Michlıtsch, J. Furr, M. R. Kozlowski, and P. Krulevitch, "Laserinduced damage of fused silica at 355 and $1064 \mathrm{~nm}$ initiated at alumınum contamination particles on the surface". Luier-Induced Damage in Optical Materiuls. SPIE 2966, 126 (1996).

23. F. Y. Génin. M R. Kozlowski, and R. Brusasco, "Catastrophic failure of contaminated fused silica optics at $355 \mathrm{~nm}$ ", Solid State Lasers for Application to Inertial Confinement Fuston, Paris. France, in press (1996).

24. T. G. Beckwith. R. D. Marangoni, J. H. Lienhard V, Mechanical Measurements: Fifth Edition, Addison-Wesley Publishing Company, Reading, MA. 1993. 


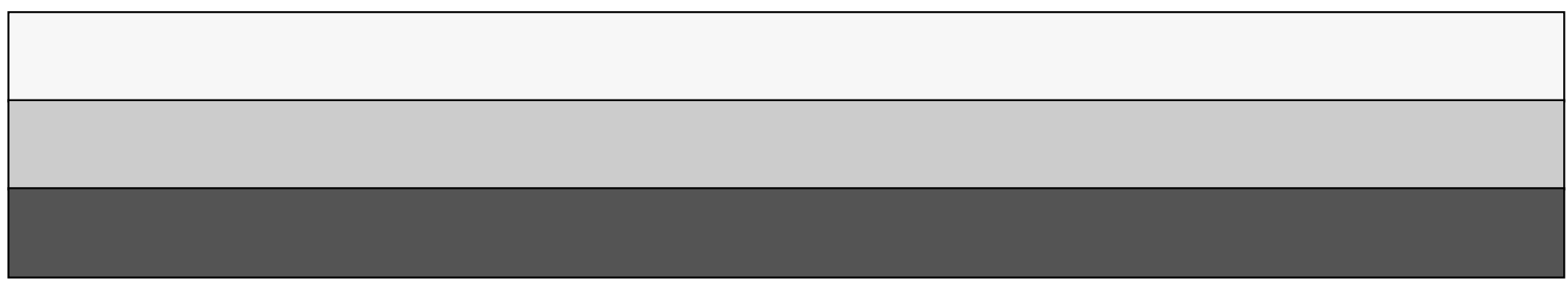

